Preprint version, Reference: Ortega, J., Vasconcelos, G., Rodrigues, H., Correia, M. Assessment of the influence of horizontal diaphragms on the seismic performance of vernacular buildings. Engineering Structures (2018). https://doi.org/10.1007/s10518-018-0318-8

\title{
Assessment of the influence of horizontal diaphragms on the seismic performance of vernacular buildings.
}

\section{Javier Ortega $^{a^{*}}$, Graça Vasconcelos ${ }^{\mathrm{a}}$, Hugo Rodrigues ${ }^{\mathrm{b}}$, Mariana Correia ${ }^{\mathrm{c}}$}

${ }^{a}$ ISISE, Department of Civil Engineering, University of Minho, Guimarães, Portugal

${ }^{\mathrm{b}}$ RISCO, School of Technology and Management, Polytechnic Institute of Leiria, Portugal

${ }^{a}$ CI-ESG Research Centre, Escola Superior Gallaecia, Portugal

* Correspondence to Javier Ortega, ISISE, Department of Civil Engineering, University of Minho, Campus de Azurém, Guimarães, 4800-058, Portugal; E-mail: javier.ortega @ civil.uminho.pt; Tel: +351 253510200

\begin{abstract}
The awareness and preservation of the vernacular heritage and traditional construction techniques and materials is crucial as a key element of cultural identity. However, vernacular architecture located in earthquake prone areas can show a particularly poor seismic performance because of inadequate construction practices resulting from economic restraints and lack of resources. The horizontal diaphragms are one of the key aspects influencing the seismic behavior of buildings because of their major role transmitting the seismic actions to the vertical resisting elements of the structure.
\end{abstract}

This paper presents a numerical parametric study adopted to understand the seismic behavior and resisting mechanisms of vernacular buildings according to the type of horizontal diaphragm considered. Detailed finite element modeling and nonlinear static (pushover) analyses were used to perform the thorough parametric study aimed at the evaluation and quantification of the influence of the type of diaphragm in the seismic behavior of vernacular buildings. The reference models used for this study simulate representative rammed earth and stone masonry vernacular buildings commonly 
Preprint version, Reference: Ortega, J., Vasconcelos, G., Rodrigues, H., Correia, M. Assessment of the influence of horizontal diaphragms on the seismic performance of vernacular buildings. Engineering Structures (2018). https://doi.org/10.1007/s10518-018-0318-8

found in the South of Portugal. Therefore, this paper also contributes for a better insight of the structural behavior of vernacular earthen and stone masonry typologies under seismic loading.

Keywords: Vernacular architecture; Seismic Behavior; Numerical analysis; Pushover parametric study; Stone masonry; Rammed earth; Horizontal diaphragms 
Preprint version, Reference: Ortega, J., Vasconcelos, G., Rodrigues, H., Correia, M. Assessment of the influence of horizontal diaphragms on the seismic performance of vernacular buildings. Engineering Structures (2018). https://doi.org/10.1007/s10518-018-0318-8

\section{Introduction}

The main focus of study presented in this paper is the vernacular architectural heritage, which consists of those dwellings and other buildings that are not designed by specialists but, on the contrary, are part of a process that involves many people over many generations and are mainly based on empirical knowledge. It was firstly defined by Rudofsky (1964) as 'architecture without architects' and can be also known as popular or traditional architecture, but vernacular is the main term used by professionals (ICOMOS 1999). Vernacular architecture makes use of available local materials and technology of the community at the time of the construction. Specifically, the work primarily addresses Portuguese vernacular architecture, where the most common traditional construction materials used are stone, wood and earth. Stone masonry, particularly granite, schist and limestone, can be observed generally in almost every region of the country. Rammed earth construction, known as 'taipa' in Portugal, and adobe masonry are extensively used in the center and south. Timber is commonly applied for the construction of the floors and roofs of most traditional buildings. Timber diaphragms are thus the most common horizontal structural elements of Portuguese vernacular architecture, and are usually coupled with earthen and stone masonry load bearing walls, which are the main vertical resisting elements of the structure.

Vernacular architecture located in seismic prone areas can be particularly vulnerable because of the generalized use of poor materials, the scarcity of resources in generally poor communities, and the poor maintenance, associated at times with lack of good construction practices. This paper addresses a critical gap in knowledge regarding vernacular architecture earthquake preparedness, with a particular focus on the Portuguese context. Portugal has a moderate seismicity characterized by small events, but several devastating earthquakes have sporadically struck the country throughout its history, as in the well-known 1755 Lisbon destructive earthquake, in 1909 Benavente earthquake and in 1969 Algarve earthquake. Therefore, more earthquakes are likely to occur in the future, endangering the vernacular heritage and, more importantly, their inhabitants. Research in vernacular architecture has predominantly been focused on building typologies and architectural spatial organization. On the other hand, the study of the seismic behavior and vulnerability of representative vernacular construction systems has consistently been ignored, since conservation efforts are often mainly 
Preprint version, Reference: Ortega, J., Vasconcelos, G., Rodrigues, H., Correia, M. Assessment of the influence of horizontal diaphragms on the seismic performance of vernacular buildings. Engineering Structures (2018). https://doi.org/10.1007/s10518-018-0318-8

placed on historical constructions and monuments. The recognition and preservation of the vernacular heritage is crucial, not only as a witness of the past but also as a privileged factor for local development, boosting local economies (Fernandes and Mateus 2012; Correia 2016).

In order to contribute to the awareness and protection of the vernacular heritage, the present work aims at: (1) obtaining a better insight on the seismic behavior of vernacular buildings by means of numerical modeling, focusing on the assessment of the role of horizontal diaphragms in transferring the lateral earthquake loads to the vertical resisting elements of the structure; and (2) proposing a classification to generally assess the seismic vulnerability of vernacular buildings according to the type of horizontal diaphragm that they present. For that matter, the paper firstly presents a brief literature review on the effect of horizontal diaphragms on the seismic performance of vernacular buildings and identifies the main constructive characteristics that define their structural behavior. Secondly, the paper introduces the modeling strategy adopted for the parametric analysis used for the study of the influence of the type of horizontal diaphragm in the seismic behavior of vernacular buildings, followed by the discussion of the results obtained. Finally, based on the results from the parametric study, the paper proposes a seismic vulnerability classification according to the type of horizontal diaphragm. This classification is compared with similar classifications defined by other researchers existing in the literature, as part of simplified seismic vulnerability assessment methods (Benedetti and Petrini 1984; GNDT 1994; Vicente 2008; Shakya 2014). These methods are important because there is a typical lack of resources assigned to the study of a traditionally underestimated and precarious vernacular heritage. Simplified seismic vulnerability assessment methods are commonly based on empiric post-earthquake damage observation and expert judgment. The use of detailed finite element (FE) modeling and nonlinear static (pushover) analysis for the definition of the seismic vulnerability assessment classes can help in strengthening the reliability of these simplified methods. 
Preprint version, Reference: Ortega, J., Vasconcelos, G., Rodrigues, H., Correia, M. Assessment of the influence of horizontal diaphragms on the seismic performance of vernacular buildings. Engineering Structures (2018). https://doi.org/10.1007/s10518-018-0318-8

\section{Horizontal diaphragms in vernacular architecture}

\subsection{Structural role of horizontal diaphragms under earthquake loading}

The serious consequences of earthquakes, such as human fatalities, are caused mainly by the collapse of poorly constructed or unsafe buildings and other man-made structures. Since vernacular buildings are mainly constructed with traditional materials using low cost and simple construction technology, they can respond poorly to earthquake ground shakings, even to those with moderate intensity (Blondet et al. 2011; Bothara and Brzev 2012; Neves et al. 2012; Sorrentino et al. 2013). Common poor quality of building materials and workmanship resulting in an inadequate connection between structural elements may lead to a loss of structural integrity. This is one of the main causes of earthquake damage in vernacular buildings. Proper connections are required to ensure the 'box-behavior' of the building so that inertial forces can be transferred among the masonry walls and they can develop in-plane resisting mechanisms. Indeed, masonry walls are the main lateral load resisting elements in vernacular buildings. This is one of the main earthquake resistant construction concepts, since the in-plane stiffness of the load bearing walls is significantly higher than their out-of-plane stiffness (Lourenço et al. 2011).

The flexibility of the traditional timber floors that are often observed in unreinforced masonry and earthen vernacular buildings leads to significant bending and shear deformations under horizontal loads (Mendes and Lourenço 2015), influencing the distribution of the forces among the vertical elements. A full multi-connected box is often very far from reality in vernacular architecture given the absence of rigid floors, causing the single walls to respond separately. This is the reason why local out-of-plane collapse mechanisms involving the overturning of the walls have been recurrently observed in past earthquakes (Blondet et al. 2011; D'Ayala and Paganoni 2011; Ingham et al. 2011; Bothara and Brzev 2012; Neves et al. 2012). When connections between horizontal diaphragms (floors and roofs) and walls are not adequate, walls are free to vibrate independently and are more susceptible to experience an out-of-plane collapse. On top of that, the loss of support often causes the partial and sometimes complete collapse of roof and floors, which is one of the major causes of fatalities during earthquakes. Figure 1 shows some of the common earthquake damages patterns associated to out-of-plane movements induced by a lack of proper diaphragm action of roofs and floors. The 
Preprint version, Reference: Ortega, J., Vasconcelos, G., Rodrigues, H., Correia, M. Assessment of the influence of horizontal diaphragms on the seismic performance of vernacular buildings. Engineering Structures (2018). https://doi.org/10.1007/s10518-018-0318-8

occurrence of premature out-of-plane failures due to flexible diaphragms and poor diaphragm-to-wall connections have also been reported experimentally by several authors (Tomazevic 1991; Mendes and Lourenço 2009; Magenes et al. 2014; Vintzileou et al. 2015).

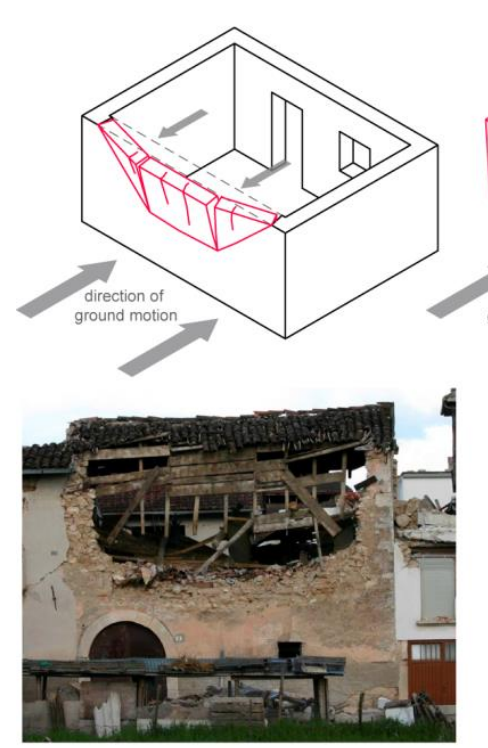

(a)

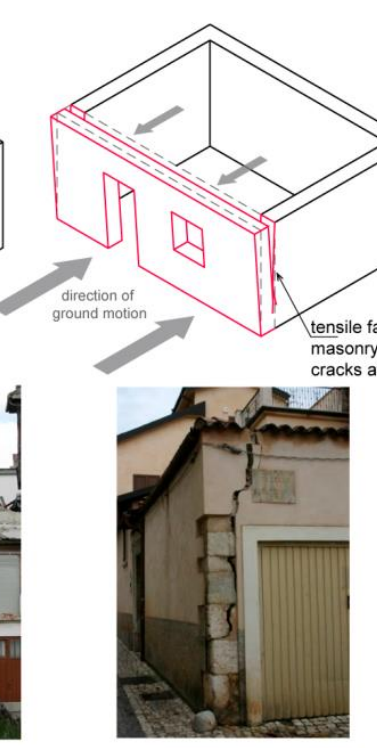

(b)

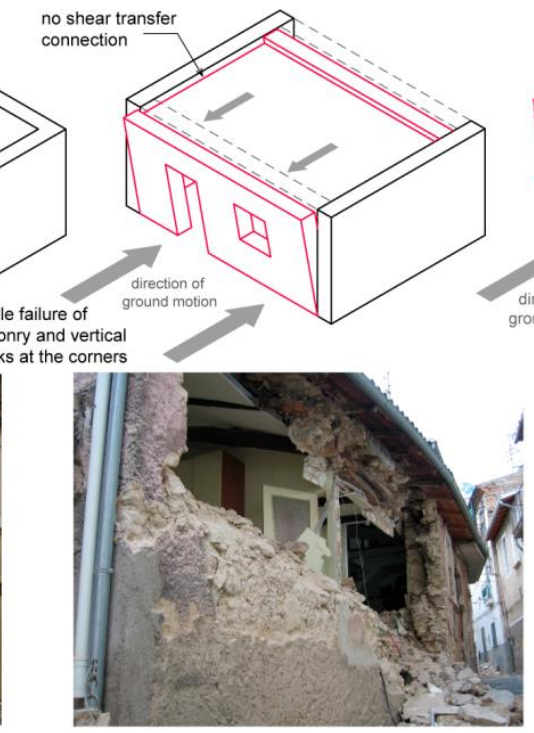

(c)

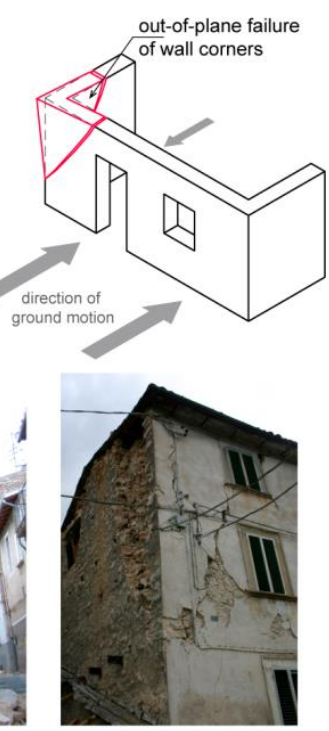

(d)

Figure 1. Common out-of-plane earthquake damage patterns illustrated with examples from L'Aquila 2009 earthquake: (a) out-of-plane mechanism in long walls; (b) global overturning of the external walls; (c) lack of anchorage between walls and horizontal diaphragms leading to the overturning of walls; and (d) out-of-plane collapse of the corner.

When an effective diaphragm-to-wall connection is ensured and the in-plane stiffness of the diaphragm is enough to redistribute the horizontal forces, engaging the walls parallel to the seismic load, the seismic behavior of vernacular buildings relies on the in-plane response of the walls. In-plane shear failure is mainly characterized by diagonal or X-cracking in the direction of the wall length. This type of shear failure is overall preferred and usually increases the overall lateral load capacity (Gattesco et al. 2007), but it can be brittle when the shear strength of the material composing the walls is low, which is the case of earthen constructions and poorly constructed stone masonry buildings. In-plane failures also depend on the geometry of the walls, such as the length to height ratio and wall thickness. The presence of openings facilitates in-plane cracking, which typically arises from the opening edges, where there is a greater concentration of stress. In the case of slender piers, rocking may occur, which consists of the rotation of the piers (Bothara and Brzev 2012). Toe crushing can also develop as a combination of rocking and diagonal cracking, resulting in the crushing and compressive 
Preprint version, Reference: Ortega, J., Vasconcelos, G., Rodrigues, H., Correia, M. Assessment of the influence of horizontal diaphragms on the seismic performance of vernacular buildings. Engineering Structures (2018). https://doi.org/10.1007/s10518-018-0318-8

failure of the masonry or rammed earth at the toe of the piers as the result of the high compressive stresses at the area. Figure 2 shows two typical examples of in-plane failure mechanisms in walls with and without openings, as observed in a real recent earthquake.

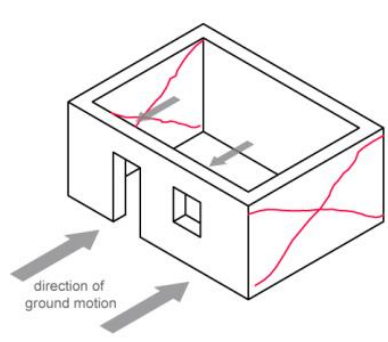

(a)

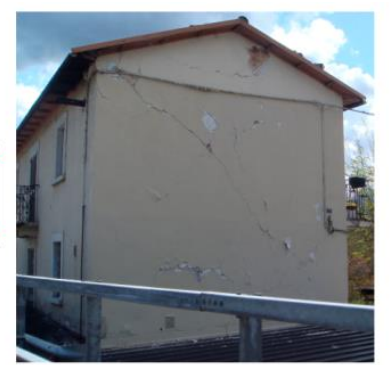

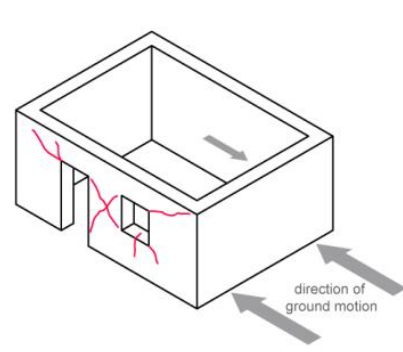

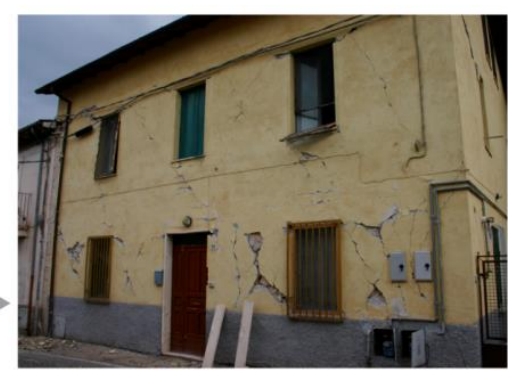

(b)

Figure 2. In-plane mechanisms resulting from an adequate diaphragmatic behavior (Ortega et al. 2017) illustrated with examples from L'Aquila 2009 earthquake: (a) In-plane shear failure in the direction of the wall length; and (b) shear diagonal and cross-shaped cracking around the openings.

\subsection{Horizontal diaphragms construction solutions and materials}

The seismic response of vernacular buildings is strongly dependent on the characteristics of timber diaphragms, since they play an important role in the distribution of horizontal loads among the resisting walls, and contribute to the development of in-plane resisting mechanisms that ensure the global stability of the building. The role of the timber diaphragms on the seismic behavior of a masonry building mainly depends on: (i) their in-plane stiffness; and (ii) the quality of their connection to the load bearing walls. Timber floor construction observed in vernacular architecture is typically very simple, being merely composed of wooden beams covered with cross boards directly nailed to the beams composing the sheathing (Figure 3a). When larger spans are required, two-way floors are commonly used, with the addition of a secondary set of timber joists perpendicular to the main beams (Figure 3b). The overall in-plane flexibility of this type of single sheathing timber floors results from the contribution of the flexural and shear deformation of the single cross boards and the rigid rotation of the board due to nails slip (Brignola et al., 2008). 
Preprint version, Reference: Ortega, J., Vasconcelos, G., Rodrigues, H., Correia, M. Assessment of the influence of horizontal diaphragms on the seismic performance of vernacular buildings. Engineering Structures (2018). https://doi.org/10.1007/s10518-018-0318-8

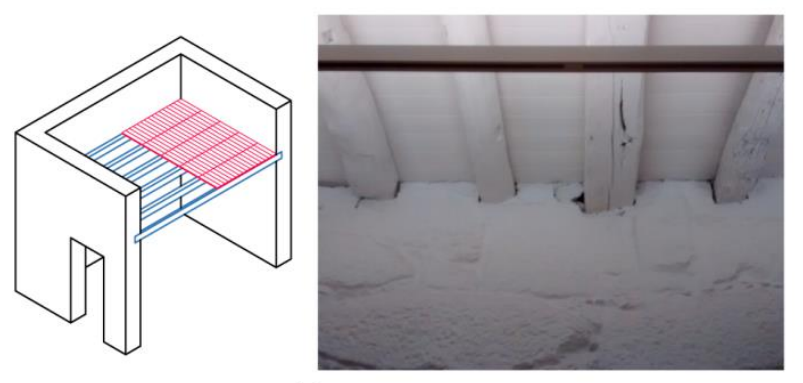

(a)

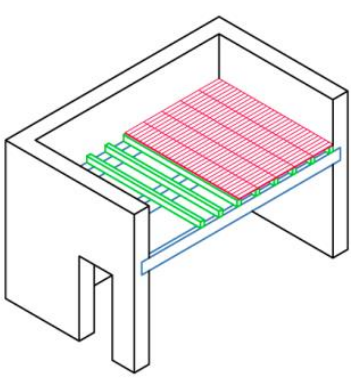

(b)

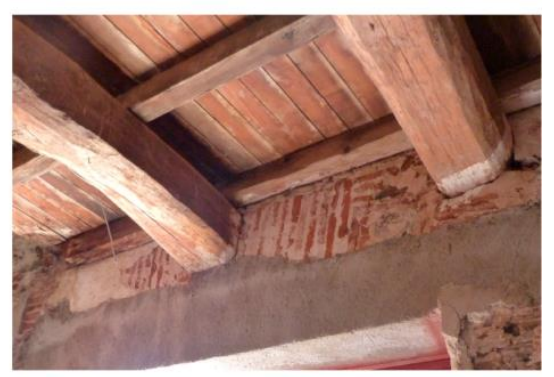

Figure 3. (a) Typical layout of traditional timber floors: wooden beams and board sheathing; and example observed in Porto, Portugal; and (b) two-way traditional timber floor with secondary set of timber joints and example observed in Vila Real de Santo António, Portugal.

Since timber beams are the main structural element composing traditional horizontal diaphragms, the behavior of the diaphragm is clearly different in the two orthogonal directions: perpendicular and parallel to the main beams axis. Likewise, in terms of construction, there are different ways of achieving a proper diaphragmto-wall connection in both directions. With respect to the connection between the primary beams and the perpendicular walls, existing timber floors are usually only linked by means of partial embedment of the timber beams within the masonry or rammed earth walls (Figure 4a). A tight connection between both elements has been traditionally ensured by using beams going through the whole width of the wall and wooden wedges anchoring the beam (Figure 4b-c) (Barbisan and Laner, 1995). Transition elements, such as perimeter timber resting plates and stone brackets, are also applied to provide a better support for the beams, redistribute stresses and improve their connection with the walls (Figure 4d-e). Metallic anchoring devices and ties can be typically observed as strengthening solutions (Figure 4f).

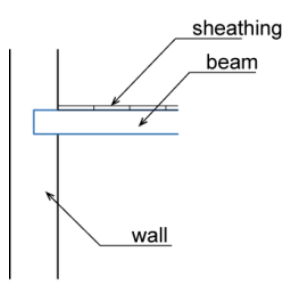

(a)

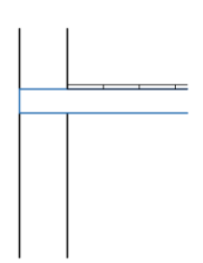

(b)

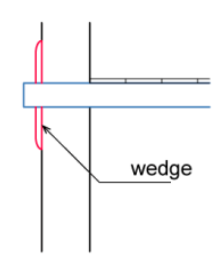

(c)

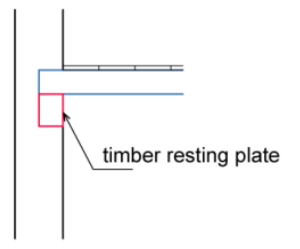

(d)

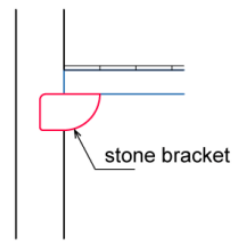

(e)

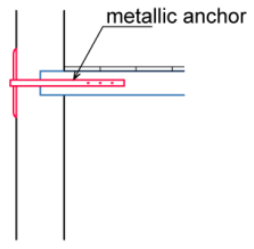

(f)

Figure 4. Different types of connections between beams and perpendicular walls (adapted from Ortega et al. 2017): (a) Partial embedment of timber beam; (b) timber beam going through the whole width of the wall; (c) timber wedges anchoring the beam; (d) timber resting plates; (e) stone brackets; (f) metallic anchoring devices. 
Preprint version, Reference: Ortega, J., Vasconcelos, G., Rodrigues, H., Correia, M. Assessment of the influence of horizontal diaphragms on the seismic performance of vernacular buildings. Engineering Structures (2018). https://doi.org/10.1007/s10518-018-0318-8

Proper detailing is also required to ensure shear transfer connection between the diaphragm and the load bearing walls parallel to the timber beams. Many times, the connection between both elements is barely nonexistent. A beam is placed adjacent to the wall but there is no structural element linking diaphragm and wall (Figure 5a). Their connection relies solely on friction, which is not enough to ensure the desired shear transfer. Metallic anchor keys and ties have been traditionally applied for this matter, connecting two or three consecutive joists to the wall (Figure 5b) (Lozano and Lozano 1995). Perimeter steel elements can also further or alternatively ensure the diaphragm-to-wall connection (Figure 5c). In cases where there is a change in the section of the wall, the beam typically rests on the set-back, which provides a better support and helps to transfer the shear through friction (Figure 5d). For two-ways floors, the secondary set of timber joists perpendicular to the main beams can be properly connected to the walls by means of partial embedment or by any of the solutions previously mentioned for connecting beams to perpendicular walls (Figure 5e).

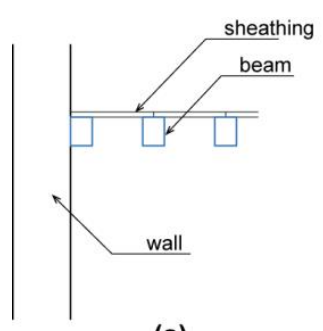

(a)

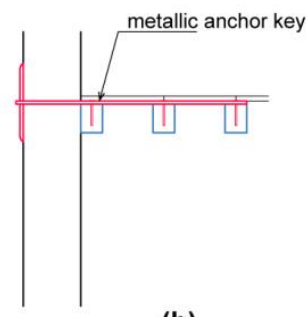

(b)

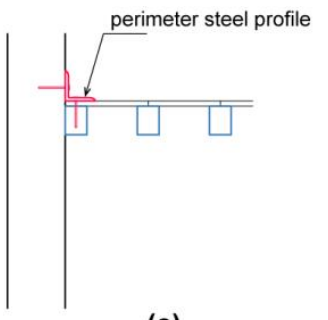

(c)

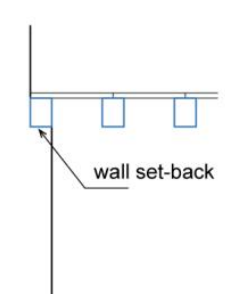

(d)

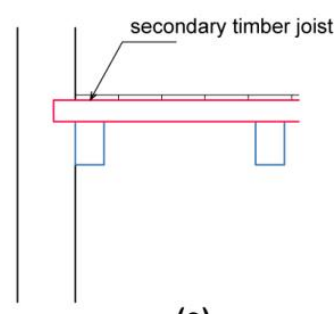

(e)

Figure 5. (a) Typical lack of connection between the beams and the parallel walls; (b) metallic anchor keys anchoring the beams to the wall; (c) use of perimeter steel profiles; (d) beams resting on the set-back of the wall; and (d) secondary timber joists partially embedded within the wall.

\subsection{Characterization of horizontal diaphragms}

The present paper is focused on the study of the role of horizontal diaphragms on the global seismic behavior of vernacular buildings by means of nonlinear numerical analysis. The seismic behavior of existing masonry and rammed earth buildings is always difficult to characterize due to factors such as the material properties, the geometry and the wall-to-wall connections, among others. Modelling the behavior of horizontal diaphragms increases the complexity of numerical models, since there is not so much information on how to simulate their effects on the seismic behavior of vernacular buildings. Moreover, there is few experimental data 
Preprint version, Reference: Ortega, J., Vasconcelos, G., Rodrigues, H., Correia, M. Assessment of the influence of horizontal diaphragms on the seismic performance of vernacular buildings. Engineering Structures (2018). https://doi.org/10.1007/s10518-018-0318-8

available in the literature on the in-plane behavior of timber flexible timber diaphragms, even though recent research focus has been placed on this subject (Brignola et al. 2012; Giongo et al. 2014; Wilson et al. 2014). This research focus has also resulted in several numerical and analytical studies on the seismic performance and characterization of timber diaphragms (Whitney and Agrawal 2015; Wilson et al. 2013) and on their influence on the seismic behavior of masonry buildings (Nakamura et al. 2017). This latter study concluded on the important effect of the diaphragms flexibility on the global seismic response of the buildings, since it directly affects the ability of the diaphragm to distribute the forces and displacements imposed to the in-plane walls. This can be directly translated into a modification of the resisting mechanisms of the building, changing out-ofplane failure modes into in-plane ones. The quantification and evaluation of the seismic response of the building in terms of maximum capacity, damage patterns and failure mechanisms, for different characteristics of the diaphragm considered is precisely the main focus of the present work.

The overall stiffness of the diaphragm was considered by Brignola et al. (2008) as the combination of the in-plane stiffness of the diaphragm itself and the stiffness of the diaphragm-to-wall connection. The influence of the quality of the diaphragm-to-wall connection will be evaluated based on the typical construction solutions discussed in the previous section. Vernacular diaphragm structural systems typically consist of wooden beams and timber cross board sheathing. Thus, the influence of the quality of the connection between the main beams and the perpendicular walls and the quality of the connection between the whole diaphragm and the perimeter walls will be assessed independently. Similarly, the influence of the stiffness of the beams will be also evaluated separately from the influence of the cross board sheathing stiffness. In summary, four aspects are considered as the most critical in defining the influence of horizontal diaphragms on the seismic behavior of vernacular buildings (Figure 6): (a) the level of connection between the timber beams and the walls $\left(\mathrm{k}_{\mathrm{c}}\right.$ ); (b) the stiffness of the beams $\left(\mathrm{k}_{\mathrm{b}}\right)$; (c) the stiffness of the diaphragm $\left(\mathrm{k}_{\mathrm{d}}\right)$; and $(\mathrm{d})$ the level of connection between the diaphragm and the wall $\left(\mathrm{k}_{\mathrm{dc}}\right)$. The following parametric analysis presented is based on variations of these four constructive characteristics of horizontal diaphragms. 
Preprint version, Reference: Ortega, J., Vasconcelos, G., Rodrigues, H., Correia, M. Assessment of the influence of horizontal diaphragms on the seismic performance of vernacular buildings. Engineering Structures (2018). https://doi.org/10.1007/s10518-018-0318-8

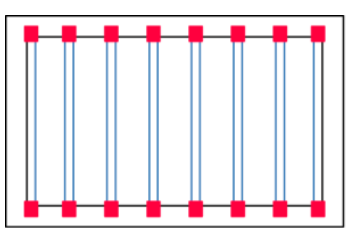

(a)

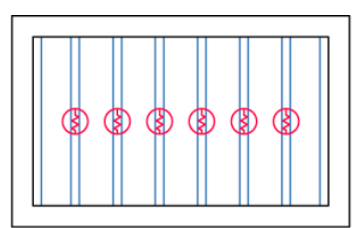

(b)

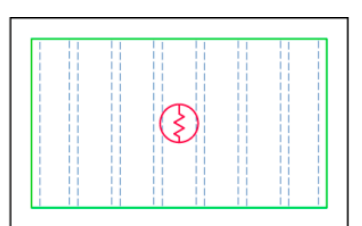

(c)

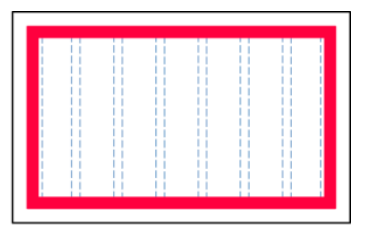

(d)

Figure 6. Four aspects considered for the evaluation of the seismic behavior of horizontal diaphragms: (a) level of connection between the timber beams and the walls $\left(\mathrm{k}_{\mathrm{c}}\right)$; (b) stiffness of the beams $\left(\mathrm{k}_{\mathrm{b}}\right)$; (c) stiffness of the diaphragm $\left(\mathrm{k}_{\mathrm{d}}\right)$; and $(\mathrm{d})$ level of connection between the diaphragm and the wall $\left(\mathrm{k}_{\mathrm{dc}}\right)$.

\section{Parametric study}

Detailed FE modeling with nonlinear static (pushover) analyses was the tool selected to perform the extensive parametric study aimed at assessing and quantifying the influence of the type of diaphragm on the seismic behavior of vernacular buildings. The parametric analysis models variations according to the four aspects defined in Figure 6 in order to assess how they influence the seismic response of the structure by comparing the results obtained with the response of a reference numerical model. This study also intends to gain a better insight of the seismic behavior and resisting mechanisms of vernacular constructions with different types of horizontal diaphragm.

FE modeling following a common macro-model approach has already been extensively and successfully applied with the aim of analyzing the seismic behavior of complex masonry and rammed earth structures (Lourenço et al. 2007, Mallardo et al. 2008; Lourenço et al. 2011; Saloustros et al. 2014; Lourenço et al. 2016). Pushover analyses with distribution of forces proportional to the mass is also a generally accepted and recommended tool used for the seismic assessment of existing masonry buildings without box behavior (Lourenço et al. 2011). It mainly consists of simulating the seismic loading as static horizontal mass proportional forces that are constant with respect to the building height. This distribution of forces tends to be overestimated at the lower level of the building (Betti and Vignoli 2011), but it is common in the analysis of masonry structures (Betti and Vignoli 2011, Lourenço et al. 2012, Saloustros et al. 2014). The loads in a pushover analysis are applied incrementally on the structure until collapse. This approach is simpler than other methods of analysis like nonlinear dynamic analysis and allows determining the ability of the building to resist the characteristic horizontal loading caused by the seismic actions taking into account the material nonlinear 
Preprint version, Reference: Ortega, J., Vasconcelos, G., Rodrigues, H., Correia, M. Assessment of the influence of horizontal diaphragms on the seismic performance of vernacular buildings. Engineering Structures (2018). https://doi.org/10.1007/s10518-018-0318-8

behavior. The response of the structure is described by the capacity or pushover curve, which represents the base shear or load factor (i.e. the ratio between the horizontal forces at the base and the self-weight of the structure) versus the displacement at the control point, which is usually the point where the highest displacements take place. Despite the limitations of simulating the earthquake loading as a set of equivalent static forces, pushover analysis is a powerful tool to assess the seismic behavior of buildings, since it can be performed with relatively low computational efforts in comparison with other more sophisticated analysis such as nonlinear dynamic analysis. Besides allowing the estimation of damage patterns and failure mechanisms of the building, it also provides an insight on the seismic capacity of the structure. In order to have a common basis for comparison of the seismic capacity of the building for different types of diaphragm, different structural limit states are defined based on the obtained capacity curve.

\subsection{Definition of limit states}

Capacity curves were built as a result of the pushover analyses performed. Performance levels and structural limit states can be defined based on the capacity curves in order to quantitatively compare the performance of the building according to the type of horizontal diaphragm evaluated. Several methods have been proposed in the literature for a quantitative definition of limit states associated to a certain damage level exhibited by the structure based on the results of nonlinear static analysis (Rota et al. 2010; Ferreira et al. 2012; Mouyiannou et al. 2014). In this work, four limit states (LS) are identified from the global response of each building, described with the pushover curve obtained in the numerical analysis:

- LS1: Represents the onset of cracking and the end of the elastic behavior (Figure 7). It can be defined also as Light Damage or Immediate Occupancy Limit State. Before this limit, the behavior of the building is essentially elastic and stable and the structure can be considered as fully operational. The beginning of cracking is assumed to start when there is a degradation of the initial stiffness of the wall up to $2 \%$. This reduction was defined after observing the first cracks that appeared in the numerical models, which are visible after a reduction of the initial stiffness of around this value, characterizing the end of the elastic behavior. It is noted that the value is relatively low but is related to the low tensile strength of the materials considered in this study. 
Preprint version, Reference: Ortega, J., Vasconcelos, G., Rodrigues, H., Correia, M. Assessment of the influence of horizontal diaphragms on the seismic performance of vernacular buildings. Engineering Structures (2018). https://doi.org/10.1007/s10518-018-0318-8

- LS2: It can be defined as the Limit State corresponding to damage limitation. This Limit State tries to depict the transition between a point where the structure is still functional and retains most of its original stiffness and strength, showing minor structural damage and cracks, and a state where significant damage is visible so that the building could not be used after without significant repair. This Limit State is calculated based on energy criteria so that the area below the three-linear curve formed by LS1, LS2 and LS3 coincides with the area below the pushover curve from LS1 to LS3. The criterion also involves that the point that defines the limit state LS2 is on the slope associated to the secant stiffness corresponding to $70 \%$ of the maximum strength (Figure 7).

- LS3: Defined by the base shear coefficient (or load factor) and displacement corresponding to the attainment of the building maximum strength (Figure 7). The building shows significant structural damage. It is usually denominated as Life Safety Limit State. The building has lost a significant amount of its original stiffness, but retains some lateral strength and margin against collapse even if it cannot be used after the earthquake.

- LS4: Ultimate limit state, related to the collapse of the building and corresponding to the point where the building resistance deteriorates below an acceptable limit, which is set at the $80 \%$ of the maximum strength, see Figure 7. It is known as Near Collapse Limit State. Repairing the building is neither possible nor economically reasonable.

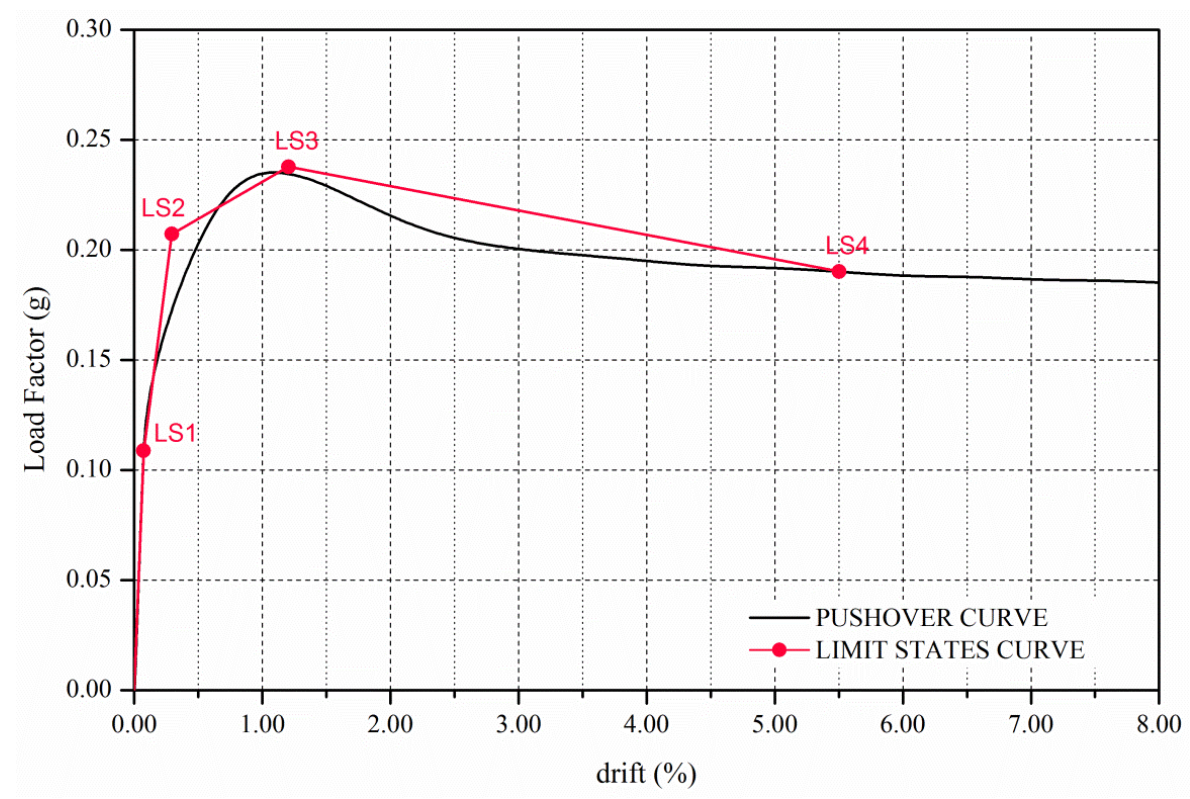

Figure 7. Identification and definition of the considered limit states on the structure pushover curve 
Preprint version, Reference: Ortega, J., Vasconcelos, G., Rodrigues, H., Correia, M. Assessment of the influence of horizontal diaphragms on the seismic performance of vernacular buildings. Engineering Structures (2018). https://doi.org/10.1007/s10518-018-0318-8

\subsection{Reference numerical model}

The reference FE model used for the parametric study was based on representative vernacular rammed earth constructions commonly found in the South Portuguese region of Alentejo. Rammed earth construction, known as 'taipa' in Portugal, has traditionally been the most widespread technique in this region and is still in use in some places. Traditional dwellings in Alentejo have generally small dimensions, simple rectangular shape and one to two floors (Correia 2002). They are simple regarding their plan configuration, little compartmentalized and present massive shapes with few or no openings, other than a single door, as a protection for the hot summers. Rammed earth walls are usually around $0.5 \mathrm{~m}$ thick and present a base course or 'soco' built in stone masonry, aimed at protecting the rammed earth from the humidity and rain penetration, by preventing the action of rising damp. Timber lintels are usually placed over windows and doors. Roofs are commonly mono-pitched roofs or gable roofs, usually presenting low slope, and made with a simple framework of timber beams. Figure 8 presents some examples of this vernacular typology. More detailed information about the geometry, structural solutions, construction materials and detailing can be found in Correia (2007).
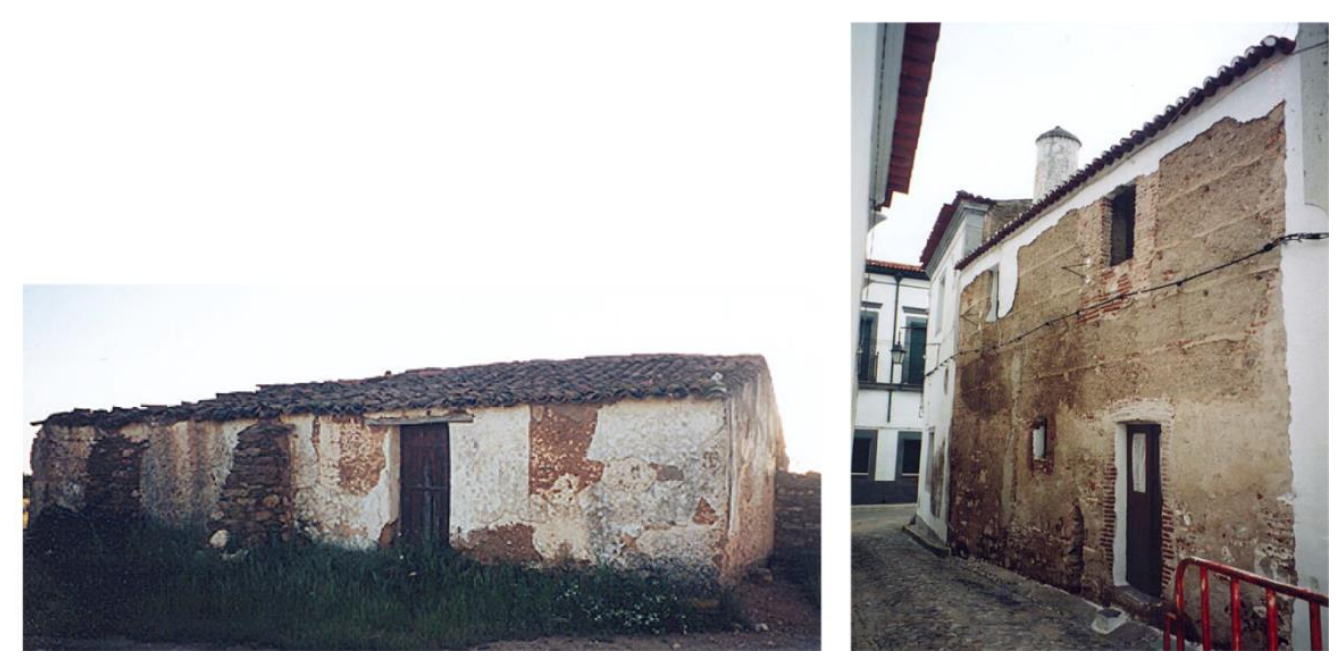

Figure 8. (left) Traditional rural one-floor rammed earth vernacular construction in Alentejo, Portugal (Correia 2007); and (right) Traditional urban two-floor rammed earth construction in Alentejo, Portugal (Correia 2002).

Initially, three reference models were prepared based on the previously described geometric and constructive characteristics: (RE1F) one-floor rammed earth building; (RE2F) two-floor rammed earth building; and (STM3F) three-floor stone masonry building, see Figure 9. Different materials and number of floors were considered in order to evaluate the influence of the type of diaphragm for different building typologies. The 
Preprint version, Reference: Ortega, J., Vasconcelos, G., Rodrigues, H., Correia, M. Assessment of the influence of horizontal diaphragms on the seismic performance of vernacular buildings. Engineering Structures (2018). https://doi.org/10.1007/s10518-018-0318-8

models were slightly simplified with respect to the buildings shown in Figure 8, so that they can represent a generic vernacular building, and easily accommodate the variations required to assess the influence of the type of diaphragm. It should be noted that the geometry and in-plan configuration was further simplified for the twoand three-floor buildings, so that the computing time could be significantly reduced. All of the models were built using DIANA software (TNO 2009). The walls of the reference numerical models are built using solid 3D elements: ten-node isoparametric solid tetrahedron elements (CTE30) with four-point integration scheme over the volume. The models have two elements within the thickness of the walls, which is established as $0.5 \mathrm{~m}$. In plan, the one-floor model has $15.5 \times 8.5 \mathrm{~m}^{2}$ and the walls height is $3.6 \mathrm{~m}$. The two and three-floor models have $8 \times 10.5 \mathrm{~m}^{2}$ in plan area and the walls height is $3 \mathrm{~m}$ at the ground floor and $2.6 \mathrm{~m}$ at the upper floors. The displacements of the elements at the base are fully restrained.

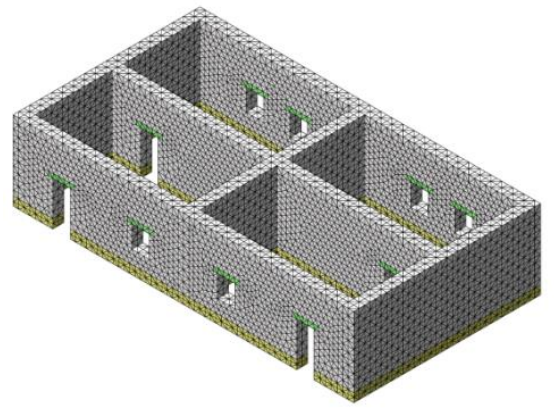

(RE1F) One-floor rammed earth building: 48,722 elements 84,731 nodes

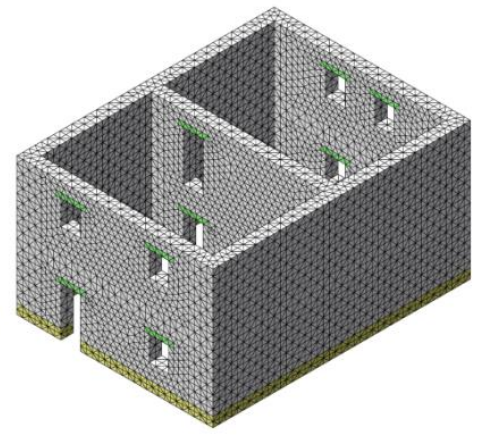

(RE2F) Two-floor rammed earth building: 41,190 elements 72,511 nodes

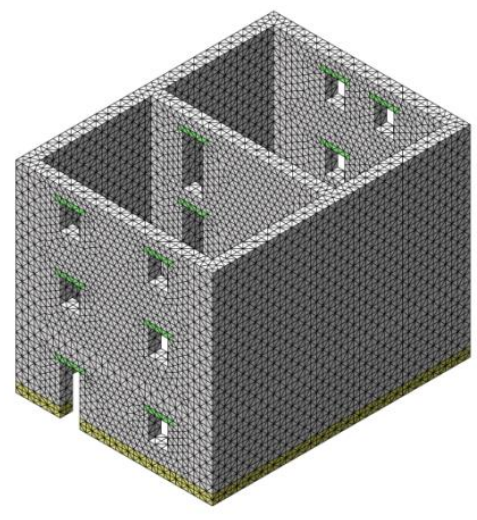

(RE2F) Three-floor stone masonry building: 60,393 elements 105,477 nodes

Figure 9. Reference numerical models.

Three different materials were initially considered for the reference models. Stone masonry is used for the base course, whose height is finally set at $0.4 \mathrm{~m}$ and is usually built with irregular schist or granite masonry. Rammed earth is used for the interior and exterior structural walls. The same material properties used for the base course are given to the stone masonry walls of the three-floor model. Timber is used for the lintels over all the openings. The material model adopted to represent the nonlinear behavior of the rammed earth and stone masonry, which are the materials considered to present nonlinear behavior, is a standard isotropic Total Strain Rotating Crack Model (TSRCM). The model describes the tensile and compressive behavior of the material with one stress-strain relationship and assumes that the crack direction rotates with the principal strain axes. It is selected because of its robustness and simplicity, and because it is very well suited for analyses which are 
Preprint version, Reference: Ortega, J., Vasconcelos, G., Rodrigues, H., Correia, M. Assessment of the influence of horizontal diaphragms on the seismic performance of vernacular buildings. Engineering Structures (2018). https://doi.org/10.1007/s10518-018-0318-8

predominantly governed by cracking or crushing of the material. The tension softening function selected is exponential and the compressive function selected to model the crushing behavior is parabolic. This constitutive model has been already successfully applied in previous analysis of complex stone masonry structures (Lourenço et al. 2007; Lourenço et al. 2015). Regarding earthen structures, few studies have adopted this type of complex models taking into account the nonlinear behavior of the material (Angulo-Ibáñez et al. 2012; Miccoli et al. 2014). Nevertheless, this material model has also proven to provide good results on complex earthen structures (Lourenço et al. 2016).

The material properties required to define the constitutive model were based on data collected from different authors. Only elastic properties are considered for the timber, as structural nonlinearities are not expected to concentrate there. An elasticity modulus of $10 \mathrm{GPa}$ and a Poisson's ratio of 0.2 were used based on typical values observed in the literature (Gomes et al. 2011; Mendes and Lourenço 2015; Wilson et al. 2013; Giongo et al. 2014). The stone masonry compressive strength and specific weight were obtained from the reference values provided by the Italian code (NTC08 2009), assuming a low-quality masonry class: an irregular masonry composed of stone units of different sizes and shapes. A compressive strength of $1 \mathrm{MPa}$ was adopted for the rammed earth, which is in agreement with the scattered values observe in the literature (Bui et al. 2008; Jaquin 2008; Braga and Estevão 2010; Gomes et al. 2011; Angulo-Ibáñez 2012; Gallego and Arto 2014; Miccoli et al. 2014). The elastic properties of the rammed earth were also based on values proposed in the literature. An elasticity modulus of $300 \mathrm{MPa}$ and a Poisson's ratio of 0.3 were adopted. The remaining nonlinear properties of both the masonry and rammed earth were computed directly from the compressive strength, based on recommendations given by (Lourenço 2009). The compressive fracture energy was obtained using a ductility factor $\mathrm{d}$ of $1.6 \mathrm{~mm}$, which is the ratio between the fracture energy and the ultimate compressive strength. The tensile strength was estimated as $1 / 10$ of the compressive strength. Finally, an average value of $0.012 \mathrm{~N} / \mathrm{mm}$ is adopted for the mode I fracture energy. Table 1 presents the material properties used for the analyses.

Table 1. Mechanical properties adopted for the three materials used in the reference model.

\begin{tabular}{lccccccc}
\hline Material & $E(\mathrm{MPa})$ & $v$ & $f_{c}(\mathrm{MPa})$ & $G_{f c}(\mathrm{~N} / \mathrm{mm})$ & $f_{t}(\mathrm{MPa})$ & $G_{f l}(\mathrm{~N} / \mathrm{mm})$ & $W\left(\mathrm{kN} / \mathrm{m}^{3}\right)$ \\
\hline Stone masonry & 1500 & 0.2 & 1.5 & 2.4 & 0.15 & 0.012 & 20 \\
Rammed earth & 300 & 0.3 & 1 & 1.6 & 0.1 & 0.012 & 20 \\
Timber & 10000 & 0.2 & - & - & - & - & 6 \\
\hline
\end{tabular}


Preprint version, Reference: Ortega, J., Vasconcelos, G., Rodrigues, H., Correia, M. Assessment of the influence of horizontal diaphragms on the seismic performance of vernacular buildings. Engineering Structures (2018). https://doi.org/10.1007/s10518-018-0318-8

\subsection{Modelling the variations on the type of horizontal diaphragm}

The variations that were considered in the reference numerical models are based on the characteristics of the horizontal diaphragm previously assumed to be influential on the seismic performance of vernacular structures: (a) beams-to-wall connection $\left(\mathrm{k}_{\mathrm{c}}\right)$; (b) beams stiffness $\left(\mathrm{k}_{\mathrm{b}}\right)$; (c) diaphragm stiffness $\left(\mathrm{k}_{\mathrm{d}}\right)$; (d) diaphragm-to-wall connection $\left(\mathrm{k}_{\mathrm{dc}}\right)$. The reference models shown in Figure 9 consider no diaphragm effect, and the floor load is simply modelled as distributed load along the walls. The possible beneficial effects of transferring the inertial forces among the orthogonal walls are not taken into consideration. This is a conservative approach but it is relevant because vernacular buildings commonly present flexible diaphragms and weak diaphragm-to-wall connections. As a result, walls are free to vibrate independently, which results in local out-of-plane collapse mechanisms. The variations introduced in the models intend to compare the response of structures presenting different types of horizontal diaphragm with the response of the reference model, which represents the worst case scenario in which a null influence of the diaphragmatic effect is assumed.

\subsubsection{Beams-to-wall connection $\left(k_{c}\right)$}

In a first step only the timber beams are modelled, assuming that the diaphragm cross board sheathing is so flexible that it is not able to redistribute the loads among the walls and has no structural role (Figure 10). The timber beams are simulated using beam elements of three nodes (CL18B), using the material properties for the timber described in Table 1. The cross section considered for the timber beams is $0.3 \times 0.225 \mathrm{~m}^{2}$ with a spacing of $1 \mathrm{~m}$. It should be noted that only the elastic properties are considered because the failure mode and nonlinearities are still expected to take place in the walls. In order to assess the influence of this first parameter, which refers to the quality of the beams-to-wall connection $\left(\mathrm{k}_{\mathrm{c}}\right)$, different levels of embedment of the beam within the wall were simulated, based on the traditional constructive solutions presented in Figure 4. Variations on this parameter represent only specific constructive details of the numerical model at the connection between the beams and the walls elements. The following different conditions at the connection were considered:

- $\quad k c 1$ : The timber beams are connected with the walls but there is no embedment within the wall. It simulates a beam supported by a timber plate or stone bracket and fixed. The connection provides equal translation of degrees of freedom between the beam and the wall. It should be noted that the connection between the beam element and the 3D solid element of the wall can only take place at one node, which is not realistic. An 
Preprint version, Reference: Ortega, J., Vasconcelos, G., Rodrigues, H., Correia, M. Assessment of the influence of horizontal diaphragms on the seismic performance of vernacular buildings. Engineering Structures (2018). https://doi.org/10.1007/s10518-018-0318-8

auxiliary horizontal beam element is simulated at this connection to redistribute the load among the surrounding nodes and avoid extremely local effects. This allows also simulating more realistically that the connection does not take place only at one node but at an area equal to the cross section of the timber beam. This auxiliary element is used for the rest of the models where the timber beams are simulated.

- $k c 2-4$ : The timber beams are partially embedded within the masonry walls with different levels of embedment going through $25 \%$, the $50 \%$ and the $75 \%$ of the wall thickness (Figure $4 a$ ). These models are only constructed for the one-floor rammed earth building. It should be noted that full connection between the embedded beam elements and wall 3D solid elements is considered in the models.

- $\quad k c 5$ : The timber beams go through the whole thickness of the wall (Figure 4a).

- $k c 6$ : The timber beams pierce the walls through the whole thickness and are anchored at the external part, simulating a traditional wooden wedge (Figure 4c). This model is only constructed for the one-floor rammed earth building.

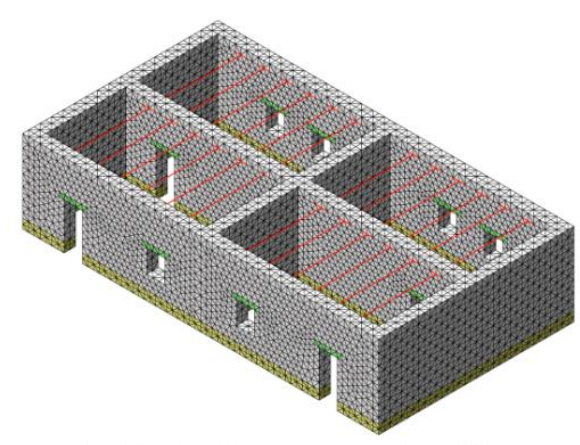

(RE1F) One-floor rammed earth building: 49,154 elements 85,379 nodes

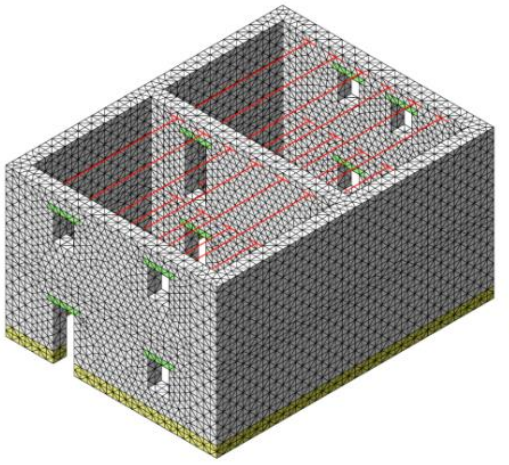

(RE2F) Two-floor rammed earth building: 45,596 elements 79,373 nodes

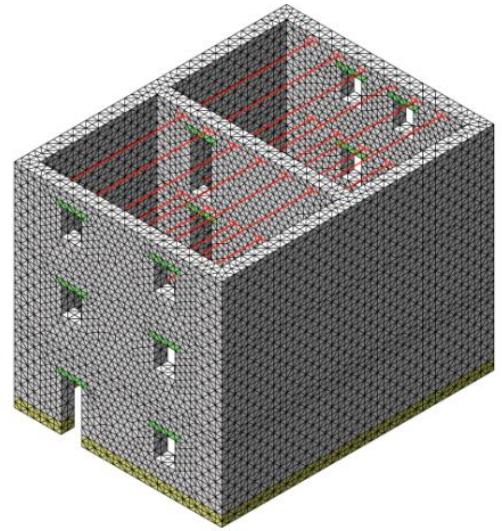

(RE2F) Three-floor stone masonry building: 67,194 elements 115,970 nodes

Figure 10. First set of models only consider the timber beams in order to evaluate the influence of: (a) the level of connection to the load bearing walls $\left(\mathrm{k}_{\mathrm{c}}\right)$; and $(\mathrm{b})$ the timber beams stiffness $\left(\mathrm{k}_{\mathrm{b}}\right)$.

\subsubsection{Beams stiffness $\left(k_{b}\right)$}

In order to assess the influence of the stiffness of the beams $\left(\mathrm{k}_{\mathrm{b}}\right)$, the Young's modulus of the timber shown in Table 1 adopted for the timber beams $\left(\mathrm{E}_{\mathrm{b}}\right)$, was divided and multiplied by two and by five. The model that assumes that the timber beams are resting on the whole width of the wall $(k c 5)$ is taken as the reference model and considers the initial material properties shown in Table 1. Four models are additionally built for this 
Preprint version, Reference: Ortega, J., Vasconcelos, G., Rodrigues, H., Correia, M. Assessment of the influence of horizontal diaphragms on the seismic performance of vernacular buildings. Engineering Structures (2018). https://doi.org/10.1007/s10518-018-0318-8

comparison: (kc5b2) 0.2 $\mathrm{E}_{\mathrm{b}}$; $(k c 5 b 3) 0.5 \mathrm{E}_{\mathrm{b}}$; $(k c 5 b 4) 2 \mathrm{E}_{\mathrm{b}}$; and $(k c 5 b 5) 5 \mathrm{E}_{\mathrm{b}}$. This effect was only evaluated for the one-floor rammed earth building.

\subsubsection{Diaphragm stiffness $\left(k_{d}\right)$}

In a second step, the structural influence of the cross-board sheathing was considered. The cross boards are simulated using triangular shell elements with six nodes (CT30S), aiming at simulating the in-plane deformability (Mendes and Lourenço 2015), see Figure 11. Again, only the elastic properties are considered for the cross-board sheathing. An elasticity modulus $\left(\mathrm{E}_{\mathrm{d}}\right)$ of $200 \mathrm{MPa}$ and a Poisson's ratio of 0.3 were adopted based on typical values observed in the literature where the diaphragm is modeled in a similar way. For example, Mendes and Lourenço (2015) proposed a value of $E_{d}$ of $160 \mathrm{MPa}$ after calibration of a numerical model using the results of an experimental shaking table test. Nevertheless, these values are also in agreement with other values observed in the literature, where $\mathrm{E}_{\mathrm{d}}$ typically lies within the range 80 to $350 \mathrm{MPa}$ (Whitney and Agrawal 2015). The thickness of the diaphragm cross boards ( $\left.t_{d}\right)$ is considered as $0.036 \mathrm{~m}$ and the specific mass is set at $750 \mathrm{~kg} / \mathrm{m}^{3}$. It should be noted that the characterization of the in-plane stiffness of typical vernacular timber diaphragms is complex, as it depends on many factors resulting from the contributions from the nails and the timber floorboard elements (Brignola et al. 2012; Wilson et al. 2013). Here, the in-plane behavior is simply defined by the assigned elastic material properties. Also, the characteristic orthotropic behavior of timber diaphragms given by the direction of the beams (Giongo et al. 2014) is partially simulated by modeling the beams independently, thus an isotropic material is considered for the diaphragm. The beams are initially considered to go through the whole thickness of the wall, using model $k c 5$ as a reference. The beams and diaphragm shell elements are considered to be fully connected, sharing common nodes. The connections between the board sheathing and the walls are also assumed to share all degrees of freedom. These simplifications are intended to reduce the amount of variables under study while providing an insight of the variability in the seismic performance of the building due to changes in the global stiffness of this diaphragm. 
Preprint version, Reference: Ortega, J., Vasconcelos, G., Rodrigues, H., Correia, M. Assessment of the influence of horizontal diaphragms on the seismic performance of vernacular buildings. Engineering Structures (2018). https://doi.org/10.1007/s10518-018-0318-8

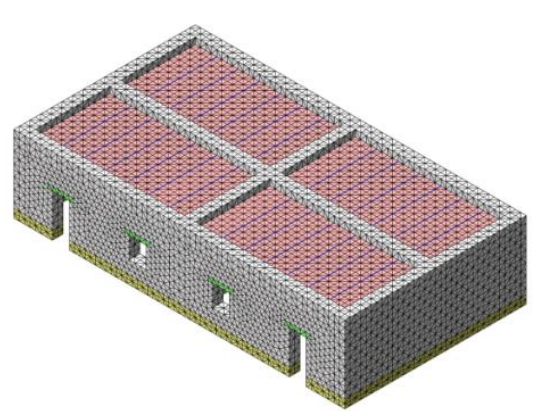

(RE1F) One-floor rammed earth building: 49,143 elements 85,514 nodes

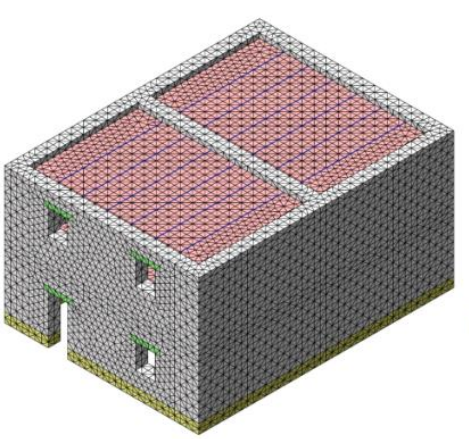

(RE2F) Two-floor rammed earth building: 49,804 elements 86,777 nodes

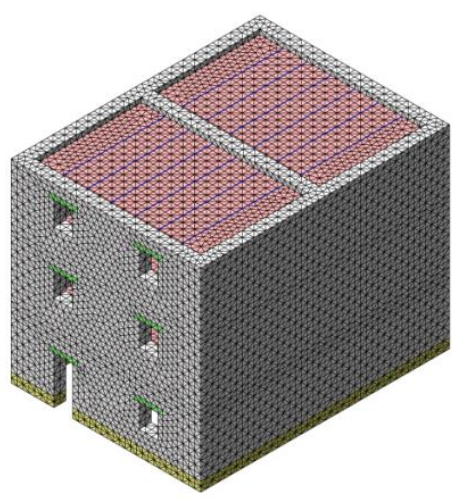

(RE2F) Three-floor stone masonry building: 73,506 elements 127,076 nodes

Figure 11. Second set of models include also the cross-board sheathing and are intended to evaluate the influence of the stiffness of the diaphragm.

In order to assess the influence of the diaphragm stiffness $\left(k_{d}\right)$, different conditions were simulated. First, since the stiffness of the diaphragm can vary to a great extent, the reference value of the Young's modulus of the diaphragm $\left(\mathrm{E}_{\mathrm{d}}\right)$ was multiplied by five (model $k c 5 d 2$ ) and divided by five and twenty (models $k c 5 d 3$ and $k c 5 d 4$ respectively). These variations provide values ranging from diaphragms being essentially rigid to almost totally flexible. Secondly, the in-plane stiffness of the timber diaphragms was decreased and increased by doubling and halving its thickness (models $k c 5 d 5$ and $k c 5 d 6$ respectively). The last two models that vary the diaphragm thickness are only constructed for the one-floor rammed earth building. Two extra models were also constructed assuming a poor beam-to-wall connection, using model $k c l$ as a reference, and varying the diaphragm stiffness: ( $k c l d l)$ uses the reference value of the diaphragm Young's modulus; and ( $k c l d 4)$ uses a value of the Young's modulus reduced by twenty times the reference value.

\subsubsection{Diaphragm-to-wall connection $\left(k_{d c}\right)$}

The low values of the Young's modulus used for the study of the influence of the stiffness board sheathing already include indirectly the effect of a poor connection between the diaphragm and the walls (Mendes and Lourenço 2015). The stiffness of the diaphragm-to-wall connection and the diaphragm stiffness can be combined into an equivalent diaphragm stiffness accounting for both contributions (Brignola et al. 2008). Nevertheless, in order to assess independently the influence of the diaphragm-to-wall connection $\left(\mathrm{k}_{\mathrm{dc}}\right)$, another set of models were built assuming an inexistent connection between the cross boards and the walls. The board sheathing was still modelled adopting the same geometry and material properties previously described and using 
Preprint version, Reference: Ortega, J., Vasconcelos, G., Rodrigues, H., Correia, M. Assessment of the influence of horizontal diaphragms on the seismic performance of vernacular buildings. Engineering Structures (2018). https://doi.org/10.1007/s10518-018-0318-8

the same triangular shell elements (CT30S), but a gap was left between the cross boards and the wall (Figure 12). This way, the sliding of the diaphragm with respect to the walls that was restrained in the previous models can occur, while the effect of a rigid diaphragm can still be taken into account. This simulates a typical traditional constructive solution, as shown in Figure 5a. The variations on this parameter only involve changes in the model construction. It is noted that, since the beams are modeled, the diaphragm is supported solely by the beams, assuming the full connection between the diaphragm and the beam nodes previously referred.

Four models were prepared assuming this type of diaphragm. The first two models consider a good beam-to-wall connection, with the beams going through the whole thickness of the wall, using model $k c 5$ as a reference: (1) the model $k c 5 d 1 \_k d c 0$ uses the reference value of the Young's modulus of the diaphragm; and (2) the model $k c 5 d 4 \_k c d 0$ uses the reduced Young's modulus that simulates a very flexible diaphragm (twentytimes lower). The two additional models consider a poor beam-to-wall connection and the beams were modelled with no embedment within the wall, using model $k c l$ as a reference: (3) the model $k c l d l \_k d c 0$ uses the reference value of the diaphragm Young's modulus; and (4) the model $k c 1 d 4 \_k c d 0$ uses the reduced Young's modulus (twenty-times lower).
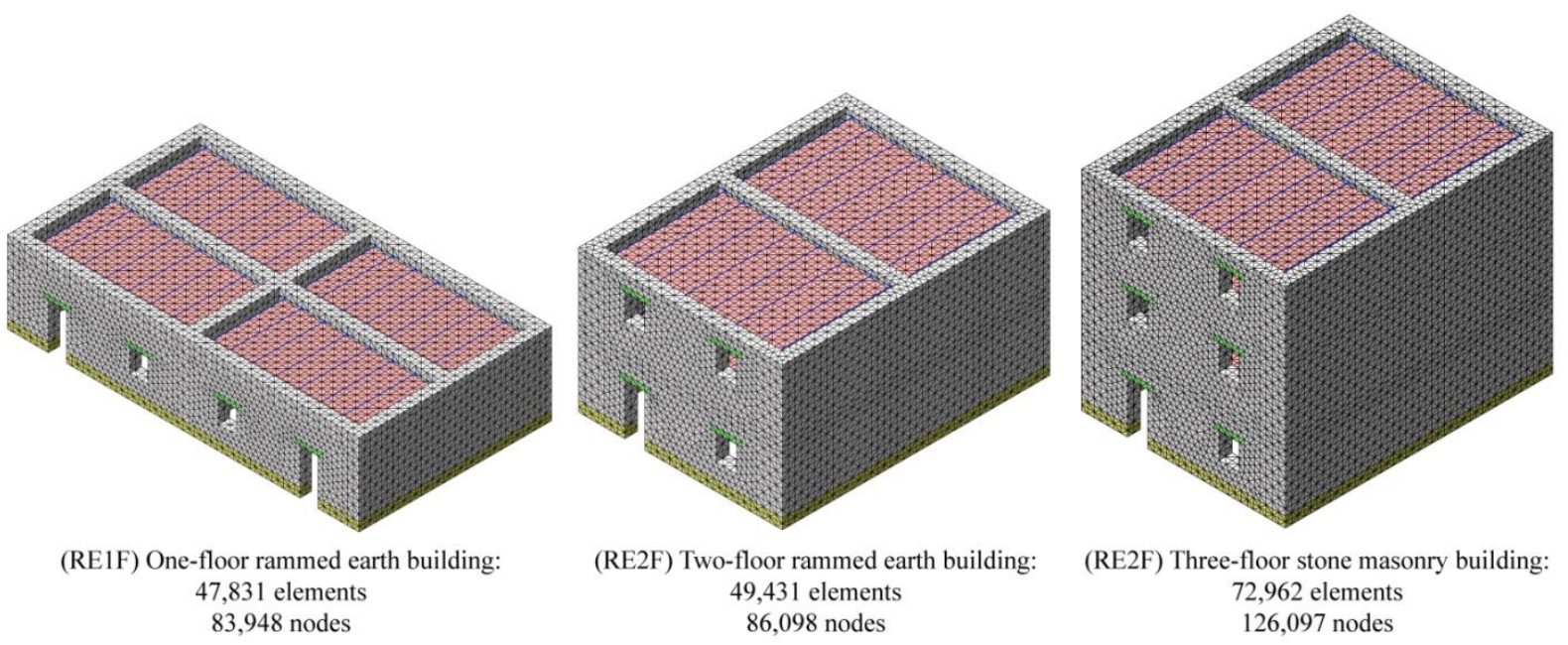

Figure 12. Third set of models allows the sliding of the diaphragm with respect to the walls and are intended to evaluate of the influence of the level of connection between the diaphragm and the walls.

\subsubsection{Summary}

The 49 models constructed according to the variations previously described are summarized in Table 2. 
Preprint version, Reference: Ortega, J., Vasconcelos, G., Rodrigues, H., Correia, M. Assessment of the influence of horizontal diaphragms on the seismic performance of vernacular buildings. Engineering Structures (2018). https://doi.org/10.1007/s10518-018-0318-8

Table 2. Summary of the different models built in order to assess the influence of the type of horizontal diaphragm in the seismic behavior of vernacular buildings.

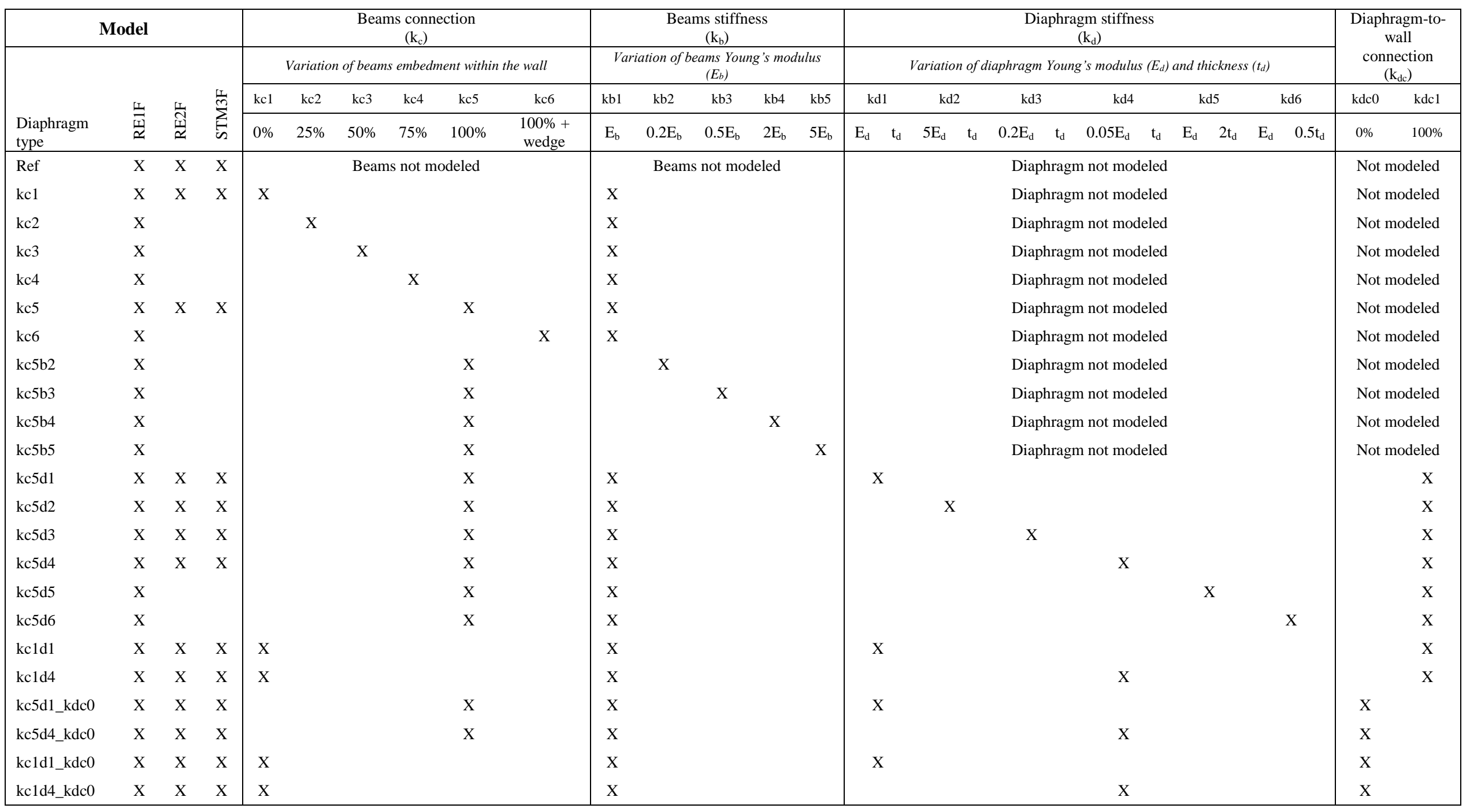


Preprint version, Reference: Ortega, J., Vasconcelos, G., Rodrigues, H., Correia, M. Assessment of the influence of horizontal diaphragms on the seismic performance of vernacular buildings. Engineering Structures (2018). https://doi.org/10.1007/s10518-018-0318-8 
Preprint version, Reference: Ortega, J., Vasconcelos, G., Rodrigues, H., Correia, M. Assessment of the influence of horizontal diaphragms on the seismic performance of vernacular buildings. Engineering Structures (2018). https://doi.org/10.1007/s10518-018-0318-8

\section{Discussion of the results}

\subsection{Damage patterns and failure mechanisms}

As aforementioned, the numerical analysis of the different models described in Table 2 was based on

4 performing pushover analyses with distribution of forces proportional to the mass. The different models constructed were tested in both orthogonal horizontal directions. The transversal direction is parallel to the direction of the beams and is referred as $\mathrm{Y}$ direction. The longitudinal direction is perpendicular to the direction of the beams and is referred as X direction. Since the variations on the type of horizontal diaphragms previously described are expected to affect the failure mode of the building, the damage patterns and failure mechanisms

9 obtained are compared and discussed. A summary of the different failure modes obtained for each model is 10 presented in Table 3.

11 Table 3. Summary of the failure modes obtained for each model showing different horizontal diaphragms.

\begin{tabular}{|c|c|c|}
\hline \multirow{2}{*}{ Failure mode } & \multicolumn{2}{|c|}{ Models } \\
\hline & Y direction & $\mathrm{X}$ direction \\
\hline \multirow{6}{*}{$\begin{array}{l}\text { Out-of-plane overturning and bending failure of the exterior wall perpendicular to the seismic } \\
\text { load. }\end{array}$} & \multirow{6}{*}{ Ref } & Ref \\
\hline & & $k c 1$ \\
\hline & & $k c 5$ \\
\hline & & $k c 5 d 4 \_k d c 0$ \\
\hline & & $k c l d 1 \_k d c 0$ \\
\hline & & $k c 1 d 4 \_k d c 0$ \\
\hline \multirow{6}{*}{$\begin{array}{l}\text { Out-of-plane overturning and bending failure of walls perpendicular to the seismic load, } \\
\text { collapsing simultaneously. }\end{array}$} & $k c 1$ & \\
\hline & $k c 2-7$ & \\
\hline & $k c 5 b 2-5$ & \\
\hline & $k c 5 d 4 \_k d c 0$ & \\
\hline & $k c 1 d 1 \_k d c 0$ & \\
\hline & $k c 1 d 4 \_k d c 0$ & \\
\hline \multirow{3}{*}{$\begin{array}{l}\text { Out-of-plane overturning and bending failure of walls perpendicular to the seismic load, } \\
\text { collapsing simultaneously. Walls parallel to the seismic load show significant in-plane } \\
\text { damage. }\end{array}$} & $k c 5 d 3-4$ & \\
\hline & $k c 1 d 4$ & \\
\hline & $k c 5 d 1 \_k d c 0$ & \\
\hline \multirow{3}{*}{$\begin{array}{l}\text { In-plane failure of the walls parallel to the seismic load. Walls perpendicular to the seismic } \\
\text { load show significant out-of-plane damage. }\end{array}$} & $k c 5 d 1-2$ & $k c 5 d 3-4$ \\
\hline & $k c 5 d 5-6$ & \\
\hline & $k c l d l$ & кcId4 \\
\hline \multirow{2}{*}{ In-plane failure of the walls parallel to the seismic load. } & & $k c 5 d 1-2$ \\
\hline & & $k c l d 1$ \\
\hline $\begin{array}{l}\text { Out-of-plane overturning and bending failure of the exterior wall perpendicular to the seismic } \\
\text { load. Walls parallel to the seismic load show significant in-plane damage. }\end{array}$ & & $k c 5 d 1 \_k d c 0$ \\
\hline
\end{tabular}


Preprint version, Reference: Ortega, J., Vasconcelos, G., Rodrigues, H., Correia, M. Assessment of the influence of horizontal diaphragms on the seismic performance of vernacular buildings. Engineering Structures (2018). https://doi.org/10.1007/s10518-018-0318-8

The representative failure modes obtained for the different models are shown in Figure 13 in terms of total displacements and crack pattern at the ultimate limit state (LS4), which is considered to be a point close to the conventional collapse of the building. With respect to the analysis performed in the transversal Y direction, the failure mode of the reference buildings where the diaphragm is simply modelled as concentrated mass consists of the out-of-plane bending failure of the exterior walls, which is characterized by extensive cracking at the base, big vertical cracks at the wall intersections, and vertical and diagonal cracks in the center of the wall.

19 When the beams are modelled the failure mode involves all the transversal walls, which collapse out-of-plane simultaneously. Finally, if the cross-board sheathing is also modelled and the in-plane stiffness is high, the failure mode is modified and involves the in-plane collapse of the walls parallel to the seismic load, showing the characteristic diagonal shear cracking. When the diaphragm is flexible or the diaphragm is poorly connected to the walls, the main failure mode consists again of the walls collapsing out-of-plane simultaneously, even though relevant in-plane damage also takes place.

Figure 14 shows the representative failure modes in the longitudinal direction that were obtained for the different models in terms of total displacements and crack pattern at the ultimate limit state (LS4). The failure mode obtained for the reference model is led by the out-of-plane overturning of the exterior walls. This failure is characterized by vertical cracks at the connection and the horizontal crack at the bottom of the wall, showing the rotation of the wall. Significant vertical cracks at the mid-span of the walls also show the out-of-plane bending

30 failure mode. For the three-floor stone masonry model, it should be noted that significant in-plane damage 31 develops even if the diaphragm is not modelled, being revealed by the typical diagonal shear cracks. This shows 32 the influence of the material properties in defining the failure mode of the building. These results show that the 33 improved material properties of the stone masonry, when compared with the other materials, together with the 34 good connection between perpendicular walls, activate the resisting mechanism that involves the in-plane walls in the seismic response of the building. 
Preprint version, Reference: Ortega, J., Vasconcelos, G., Rodrigues, H., Correia, M. Assessment of the influence of horizontal diaphragms on the seismic performance of vernacular buildings. Engineering Structures (2018). https://doi.org/10.1007/s10518-018-0318-8
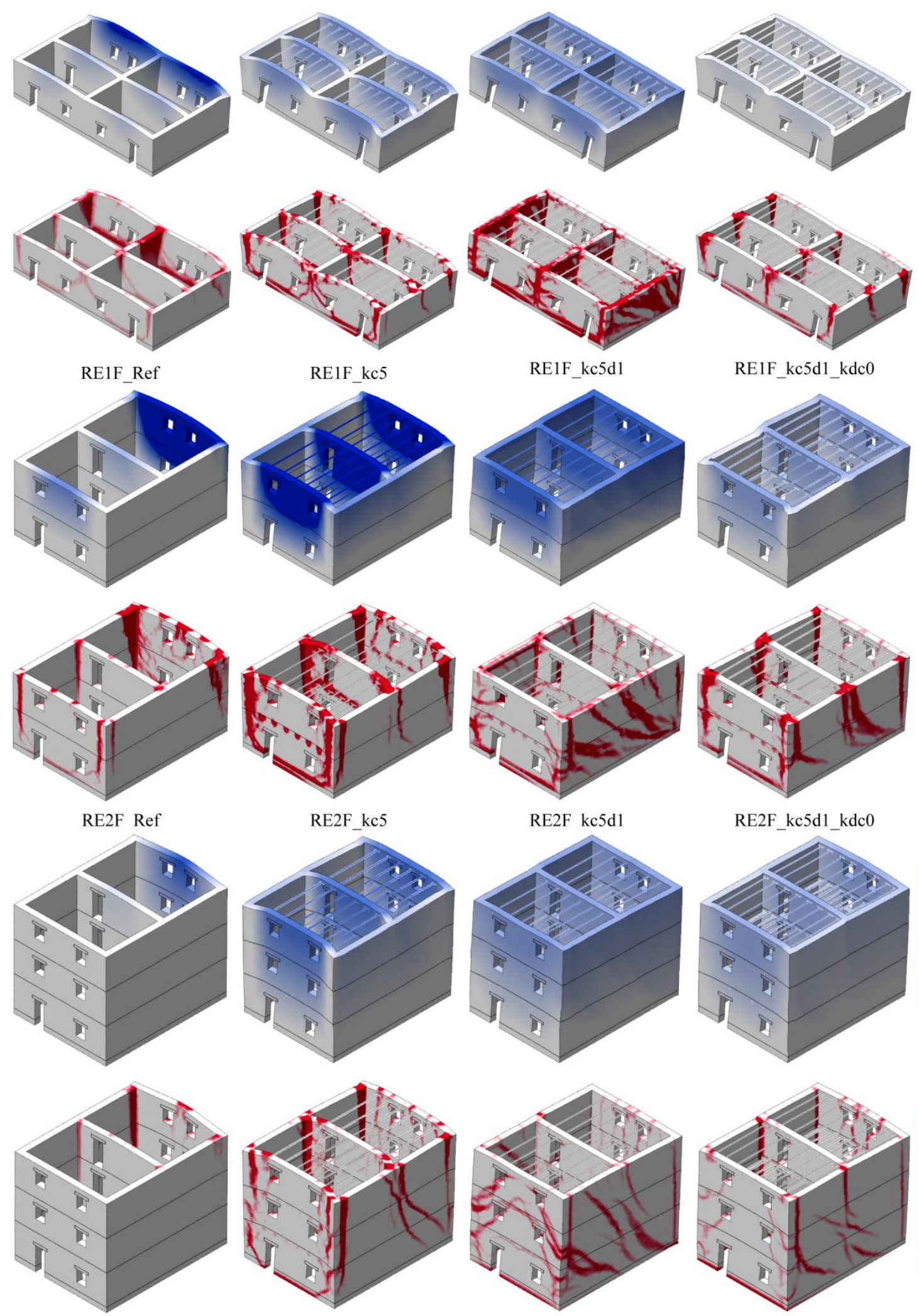

STM3F_kc5d1

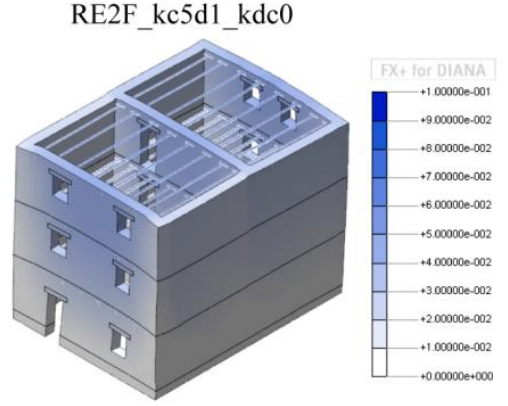

STM3F_kc5

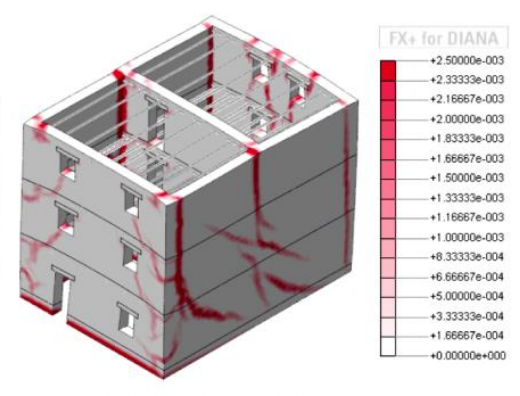

STM3F_kc5d1_kdc0

37 Figure 13. Representative failure modes in the transversal direction obtained for the different models varying the type of horizontal diaphragm in terms of: (blue) total displacements (scale in m); and (red) crack pattern (crack width scale in m), at the ultimate limit state (LS4). 
Preprint version, Reference: Ortega, J., Vasconcelos, G., Rodrigues, H., Correia, M. Assessment of the influence of horizontal diaphragms on the seismic performance of vernacular buildings. Engineering Structures (2018). https://doi.org/10.1007/s10518-018-0318-8
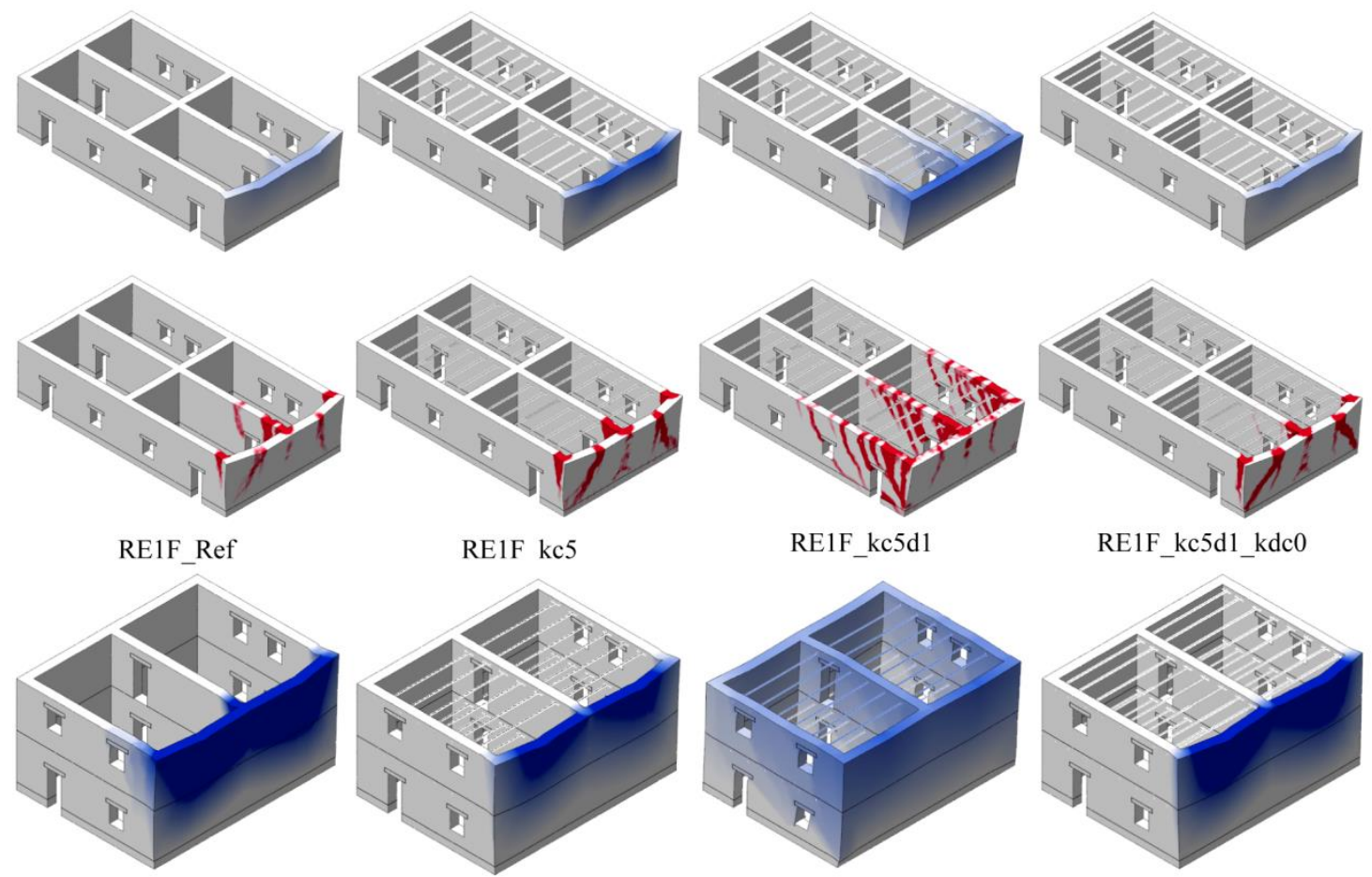

RE1F_kc5d1_kdc0
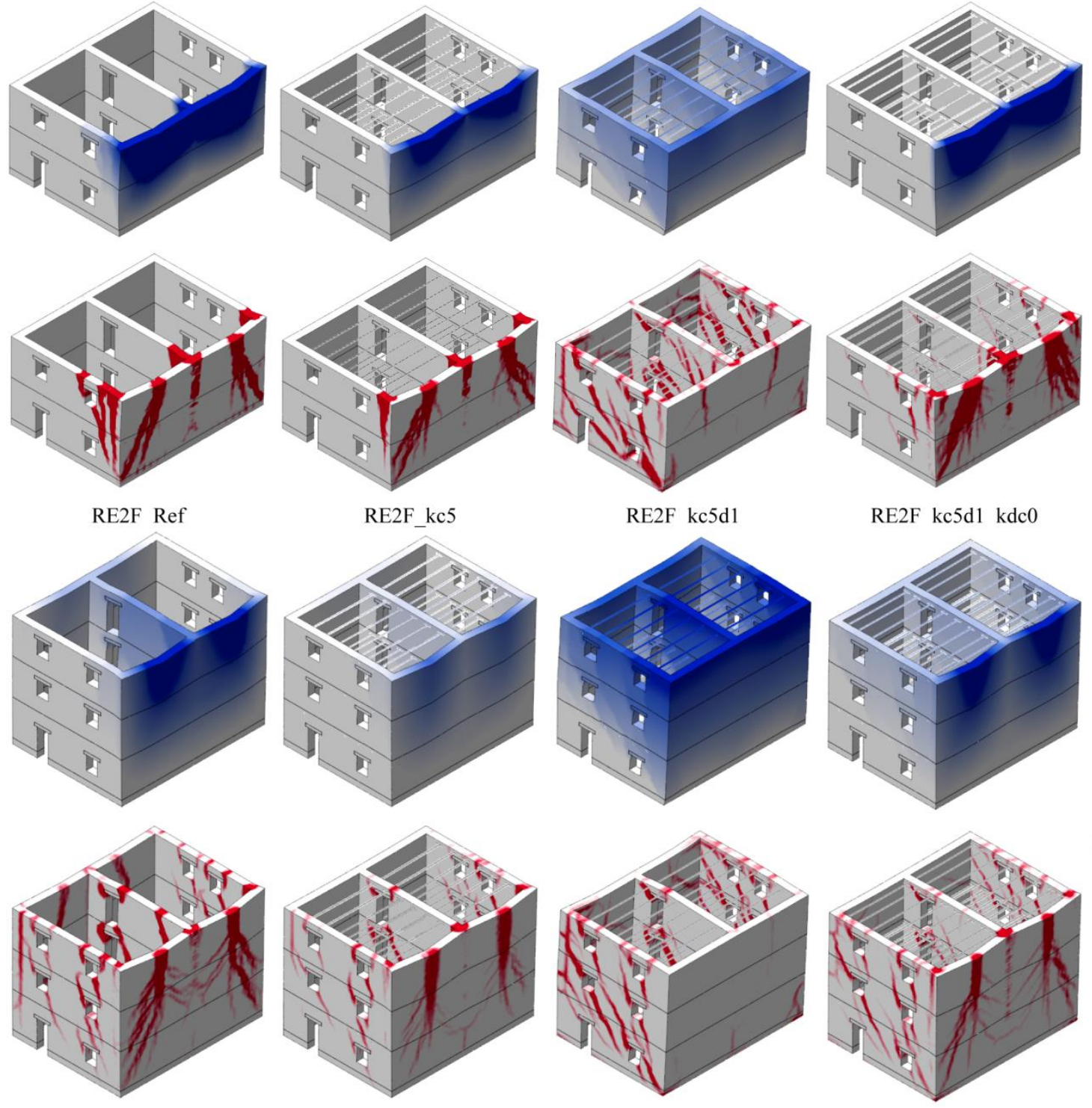

STM3F_kc5d1
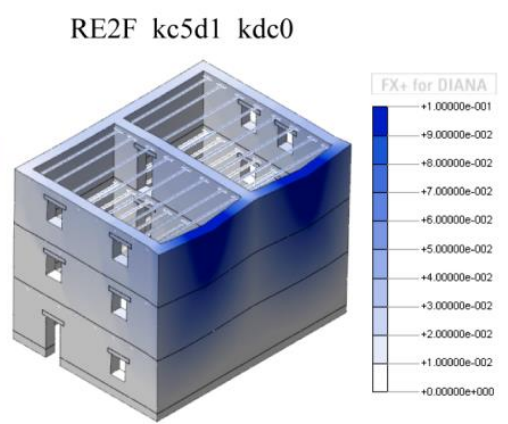

STM3F_kc5

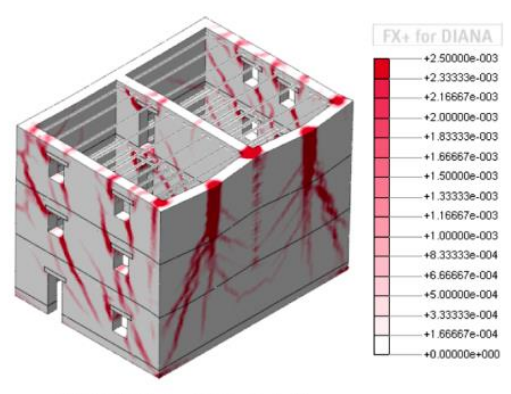

41 Figure 14. Representative failure modes in the longitudinal direction obtained for the different models varying the type of horizontal diaphragm in terms of: (blue) total displacements (scale in m); and (red) crack pattern (crack width scale in m), at the ultimate limit state (LS4). 
Preprint version, Reference: Ortega, J., Vasconcelos, G., Rodrigues, H., Correia, M. Assessment of the influence of horizontal diaphragms on the seismic performance of vernacular buildings. Engineering Structures (2018). https://doi.org/10.1007/s10518-018-0318-8

Since the loading direction is perpendicular to the beams, their influence is almost negligible and they do not have the beneficial coupling action observed in the transversal direction. The failure mode obtained for the models where only the beams are modelled is thus still governed by the out-of-plane failure of the walls perpendicular to the seismic load. However, when the whole diaphragm including the cross boards is modelled with enough stiffness to be able to transfer the load to the walls parallel to the horizontal load, the failure mode changes and consists of a very clear in-plane failure characterized by the common diagonal cracking in the direction of the wall length, arising from the edges of the openings. In this case, the damage at the connection between perpendicular walls is highly reduced and a greater number of walls are involved in the seismic response. When the diaphragms are flexible or poorly connected to the walls, the main failure mode consists again of the out-of-plane overturning of the exterior walls perpendicular to the horizontal load. Nevertheless, the presence of the diaphragm partially activates the walls parallel to the seismic load and relevant in-plane damage can be observed, particularly in the models with two and three floors.

\subsection{Building of capacity curves and identification of limit states}

As a result of the different pushover analyses performed for each model in both orthogonal horizontal directions, capacity curves were obtained, and the limit states (LS1 to LS4) were identified, following the procedure previously described and shown in Figure 7. Therefore, from the capacity curves, four-linear curves could be derived by defining the points associated to the four structural limit states. These equivalent curves allow an easier comparison of the structural response of the different models in terms of load factors and drift corresponding to the four limit states.

Four-linear curves were constructed for each pushover analysis performed in all models considered in the parametric study. As previously referred, the criterion adopted to build the capacity curves of the buildings was the selection of the node showing the highest displacements. However, it should be noted that this node varies according to the collapse mechanism obtained, which differs when the buildings present different types of diaphragms. Thus, the curves are representative of the global structural behavior of the different buildings subjected to horizontal loading, not individual structural elements composing the buildings. Figure 15 shows the results in the transversal Y direction for the one-floor rammed earth building, which evaluates independently the 
Preprint version, Reference: Ortega, J., Vasconcelos, G., Rodrigues, H., Correia, M. Assessment of the influence of horizontal diaphragms on the seismic performance of vernacular buildings. Engineering Structures (2018). https://doi.org/10.1007/s10518-018-0318-8

influence of the four variations defined for horizontal timber diaphragms that are considered to affect the seismic performance of the structure: (a) influence of the beams-to-wall connection $\left(\mathrm{k}_{\mathrm{c}}\right)$; (b) influence of the beams stiffness $\left(\mathrm{k}_{\mathrm{b}}\right)$; (c) influence of the diaphragm stiffness $\left(\mathrm{k}_{\mathrm{d}}\right)$ according to the variation of the diaphragm Young's modulus $\left(\mathrm{E}_{\mathrm{d}}\right)$; (d) influence of the diaphragm stiffness $\left(\mathrm{k}_{\mathrm{d}}\right)$ according to the variation of the diaphragm thickness $\left(\mathrm{t}_{\mathrm{d}}\right)$; and (e) influence of the diaphragm-to-wall connection $\left(\mathrm{k}_{\mathrm{dc}}\right)$ for variable beams-to-wall connection and variable diaphragm stiffness.

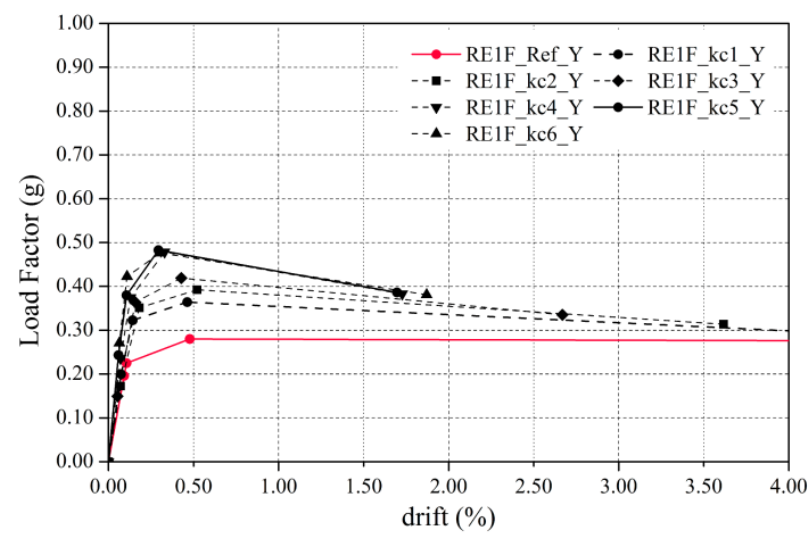

(a) Variation of beams-to-wall connection $\left(\mathrm{k}_{\mathrm{c}}\right)$

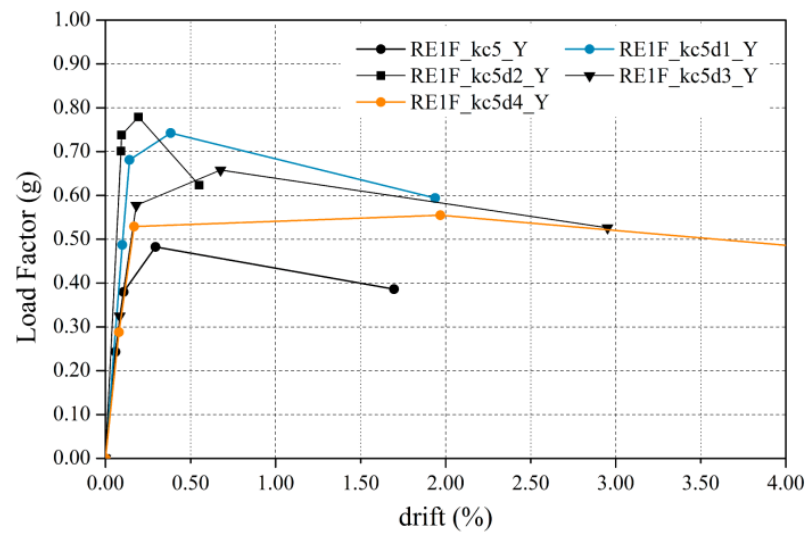

(c) Variation of diaphragm Young's modulus $\left(\mathrm{E}_{\mathrm{d}}\right)$

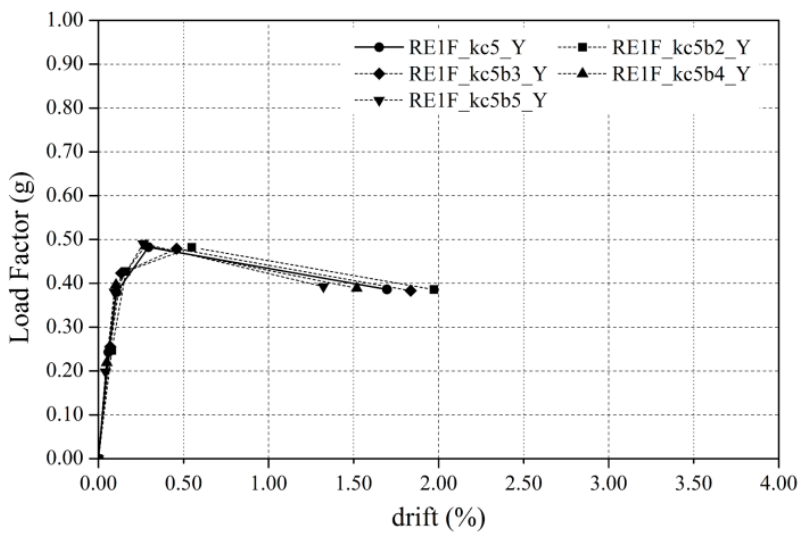

(b) Variation of beams Young's modulus $\left(\mathrm{E}_{\mathrm{b}}\right)$

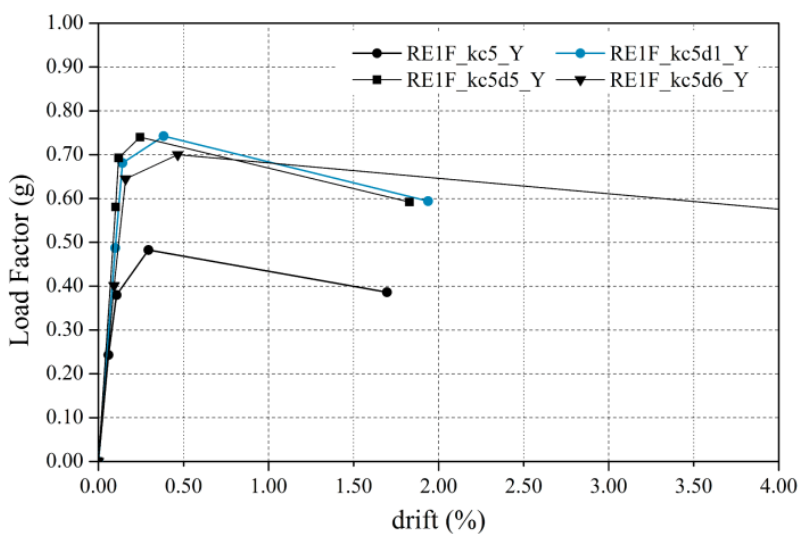

(d) Variation of diaphragm thickness $\left(\mathrm{t}_{\mathrm{d}}\right)$

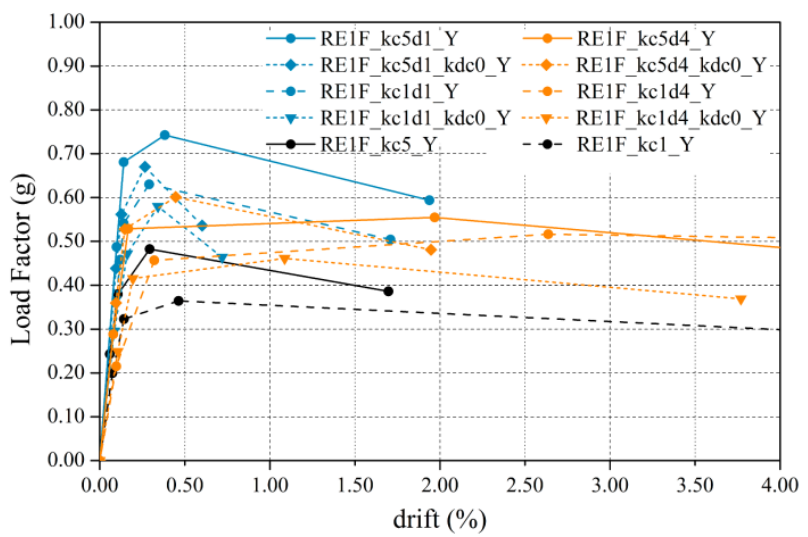

(e) Variation of diaphragm-to-wall connection $\left(\mathrm{k}_{\mathrm{dc}}\right)$ 
Preprint version, Reference: Ortega, J., Vasconcelos, G., Rodrigues, H., Correia, M. Assessment of the influence of horizontal diaphragms on the seismic performance of vernacular buildings. Engineering Structures (2018). https://doi.org/10.1007/s10518-018-0318-8

77 Figure 15. Results in the transversal direction for the one-floor rammed earth building in terms of four-linear capacity curves constructed based on the computed limit states.

The results clearly show the influence that the different levels of beams-to-wall connections have on the seismic resistance of the building (Figure 15a). Considering proper connections of the beams involving the whole section of the wall (such as models $k c 5$ and $k c \sigma$ ), an increase of approximately $75 \%$ on the capacity of the building is achieved with respect to the model without effective connection of the beams. By increasing its embedment length, the beams manage to activate a bigger portion of the masonry wall and are able to take greater axial force before causing the tensile failure of the masonry surrounding the connection with the beam, known as cone failure, achieving a better redistribution of the load among the connected parallel walls. On the other hand, the stiffness of the beams barely varies the behavior (Figure 15b). As expected, the diaphragm action that is achieved by modeling also the cross-boards has a great influence on the seismic behavior of the buildings. The presence of a rigid diaphragm almost doubles the capacity of the model in which only the timber beams are considered. Figure 15c shows the sensitivity of the building to variations in the diaphragm stiffness, i.e. variations of the diaphragm Young's modulus $\left(E_{d}\right)$. If the stiffness of the diaphragm is divided by five and by twenty (simulating very flexible diaphragms), the failure mode is mainly controlled by the out-of-plane collapse of the walls perpendicular to the seismic load. However, the capacity of the building increases with respect to the models where the diaphragm is not modelled because the walls parallels to the horizontal loading are also activated in the response and show significant in-plane damage. On the other hand, the variation of the thickness of the diaphragm $\left(t_{d}\right)$ has a lesser influence on the building response (Figure 15d), which should be associated to a lower increment and decrease of the diaphragm stiffness. Finally, Figure 15e shows the decreasing capacity of the structure when the level of connection between the structural elements is compromised in some way. For example, the structure presenting a rigid diaphragm well-connected to the walls but beams poorly coupled with the walls (model $k c l d l$ ) presents a lower capacity than the model presenting a rigid diaphragm well-connected (model $k d 5 d l$ ). If, additionally, the cross-board sheathing is also poorly 101 connected to the walls (model $k c l d l_{-} k d c 0$ ), the seismic capacity of the structure is further reduced. 
Preprint version, Reference: Ortega, J., Vasconcelos, G., Rodrigues, H., Correia, M. Assessment of the influence of horizontal diaphragms on the seismic performance of vernacular buildings. Engineering Structures (2018). https://doi.org/10.1007/s10518-018-0318-8

104 included in the same graph in order to be compared and evaluated simultaneously. From the analysis in the 105 transversal $(\mathrm{Y})$ direction, similar patterns of variations are noted for all the models presenting different number 106 of floors. Even the percentage of variation is very similar for all of them. The maximum difference in terms of 107 maximum capacity between the reference model (model Ref) and the model presenting a rigid diaphragm wellconnected to the walls (model $k c 5 d 2$ ) is almost the same for the three models and ranges between $30 \%$ and $40 \%$.

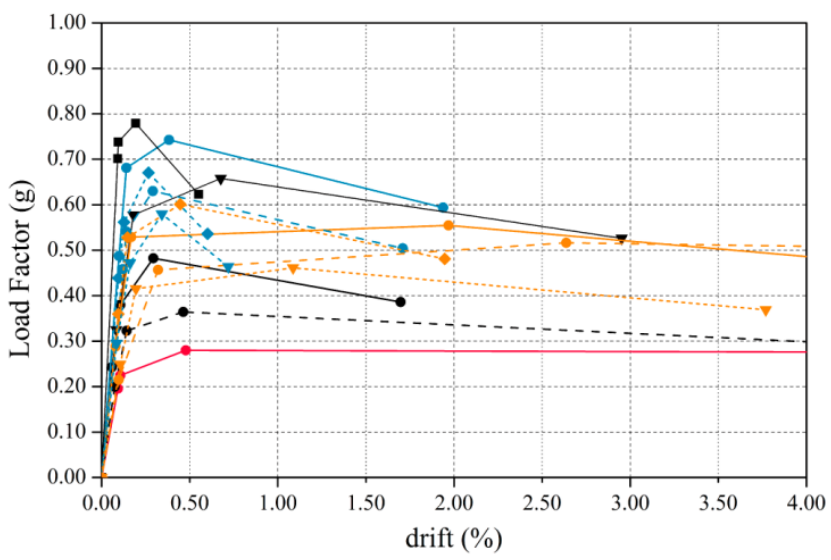

(a) RE1F_Y

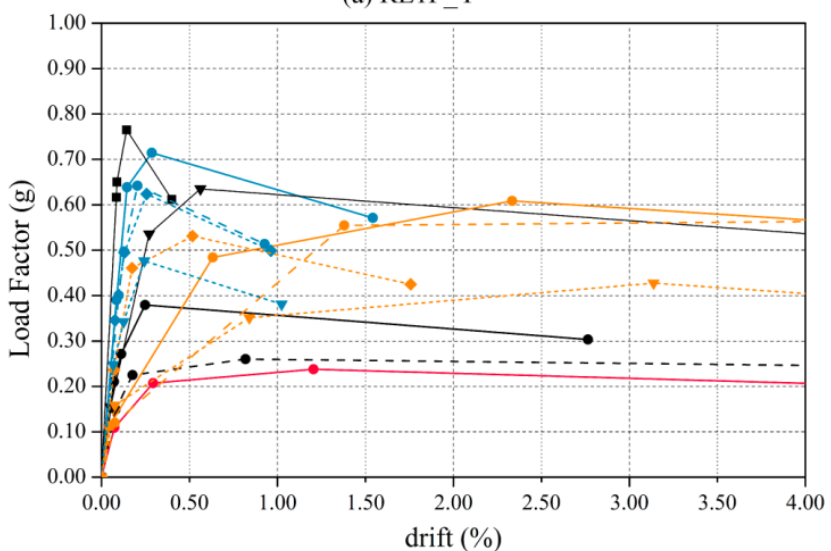

(c) RE2F_Y

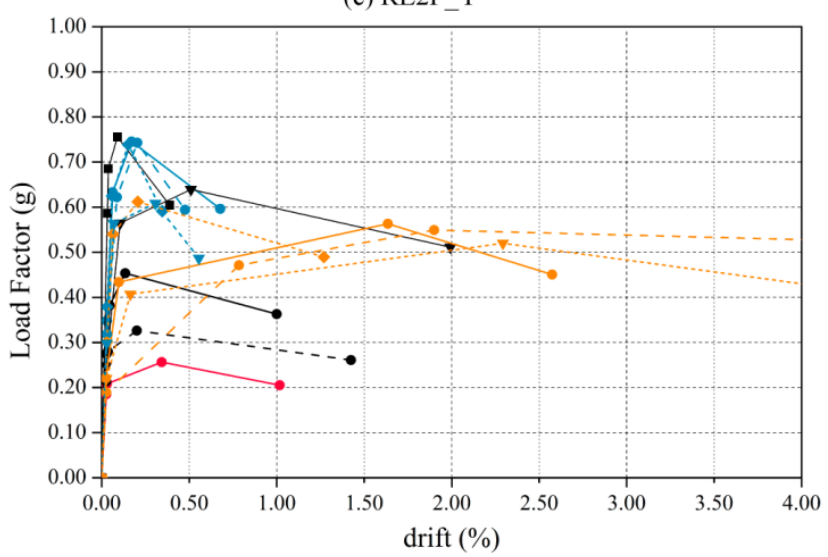

(e) STM3F_Y

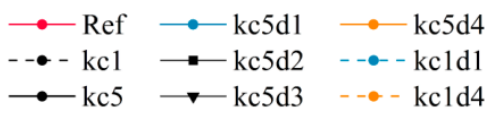

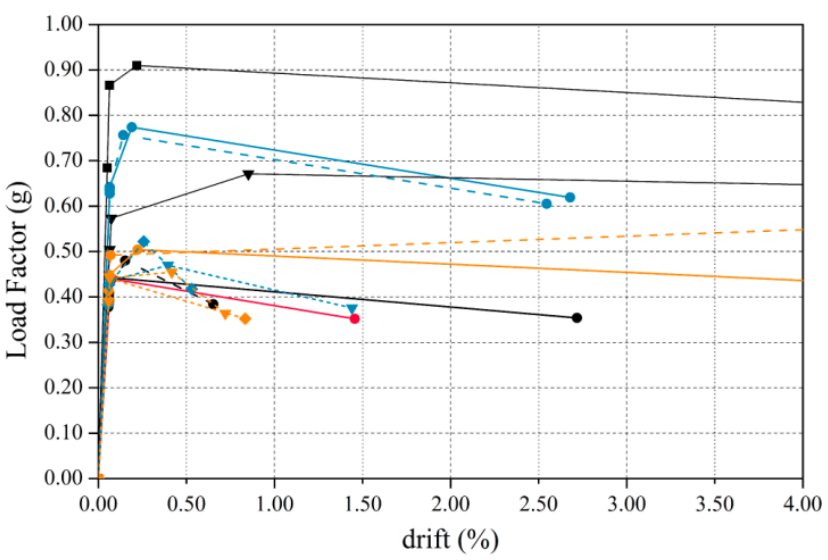

(b) RE1F_X

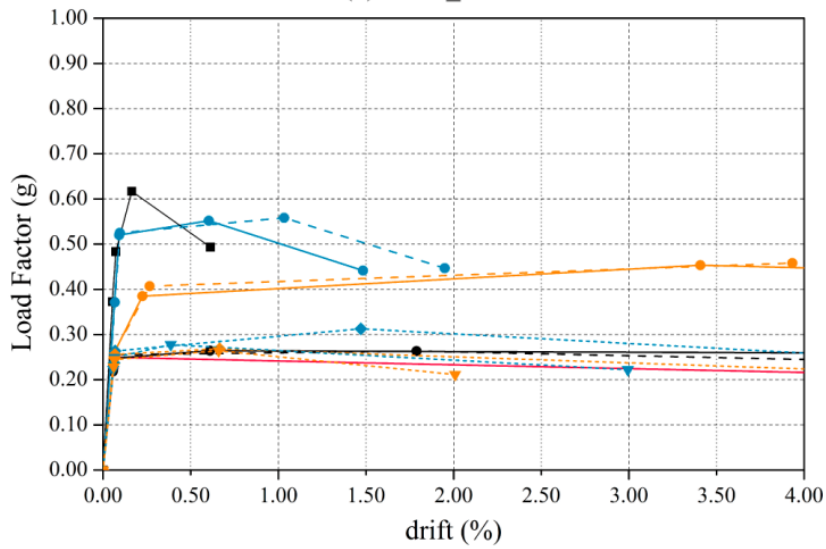

(d) RE2F_X

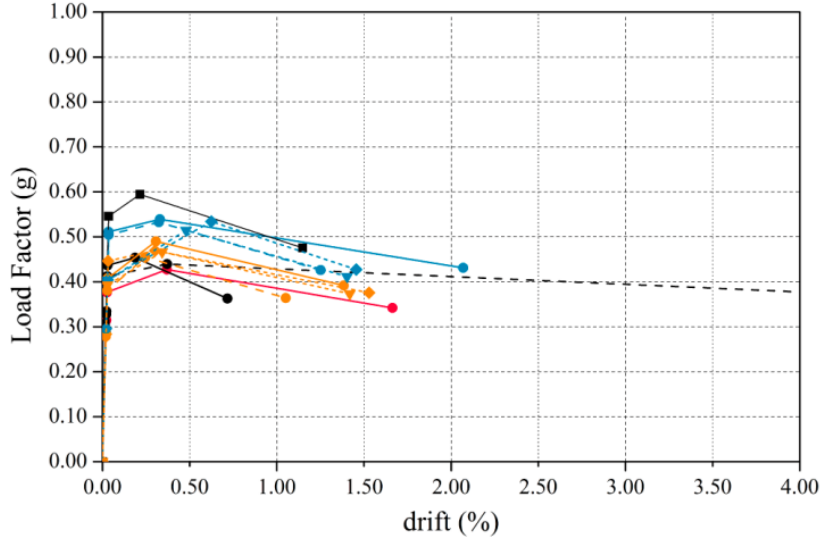

(f) STM3F_X

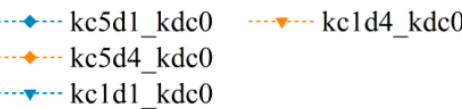


Preprint version, Reference: Ortega, J., Vasconcelos, G., Rodrigues, H., Correia, M. Assessment of the influence of horizontal diaphragms on the seismic performance of vernacular buildings. Engineering Structures (2018). https://doi.org/10.1007/s10518-018-0318-8

110 Figure 16. Results in terms of four-linear capacity curves constructed based on the computed limit states for all

111 models in both orthogonal directions.

With respect to the longitudinal $(\mathrm{X})$ direction, as it could be expected, results show that the beam-to-

113 wall connection has almost no influence when the buildings are subjected to lateral loading perpendicular to the

114 beams. Results barely vary for all models where the diaphragm is not modeled or the diaphragm-to-wall

115 connection is considered to be negligible. This is consistent with the common out-of-plane failure of the exterior

116 wall perpendicular to the seismic load observed in the building (Table 3). However, the influence of modeling

117 the diaphragm sheathing is still critical. For example, the maximum capacity of model $R E 2 F \_k c 5 d 2$ in the

118 longitudinal direction is more than two times the maximum capacity of model $R E 2 F \_k c 5$, in which only the

119 timber beams are considered. Figure $16 \mathrm{~b}$ and $\mathrm{d}$ show that the variation of the stiffness of the diaphragm results

120 in significant differences in the seismic capacity in terms of Load Factors. The response of the model with rigid

121 or flexible diaphragm well-connected to the walls is basically the same if the beams are properly or poorly

122 coupled with the walls, see for example models $R E 2 F_{-} k c 5 d 1$ and $R E 2 F \_k c l d 1$. This confirms again that the

123 influence of the beams-to-wall connection is almost zero for the analyses in this direction. In the case of the

124 three-floor stone masonry model, the influence of the diaphragm stiffness on the seismic behavior of the

125 building is lower when compared to the other two models. This can be explained by the ability of the

126 longitudinal walls to contribute to the seismic resistance of the building with the activation of in-plane

127 mechanisms, as shown in Figure 14, even when the timber diaphragms are not modeled. This can be related

128 with the better material properties assumed for the stone masonry, which are high enough to activate the in-

129 plane behavior of the walls so that they can contribute to the seismic resistance of the building.

\subsection{Analysis of the Load Factor variations}

The values of load factor corresponding to each limit state obtained for the different models are compared in order to have a better insight on the variation of the capacity of the building according to the

133 different types of horizontal diaphragm considered. It should be mentioned that the load factors can be directly

134 associated to equivalent static horizontal loads that the buildings can withstand before reaching specific

135 structural limit states. Therefore, they are adopted as the basis of comparison among the different buildings in 
Preprint version, Reference: Ortega, J., Vasconcelos, G., Rodrigues, H., Correia, M. Assessment of the influence of horizontal diaphragms on the seismic performance of vernacular buildings. Engineering Structures (2018). https://doi.org/10.1007/s10518-018-0318-8 states for each model and for the transversal and longitudinal loading direction.

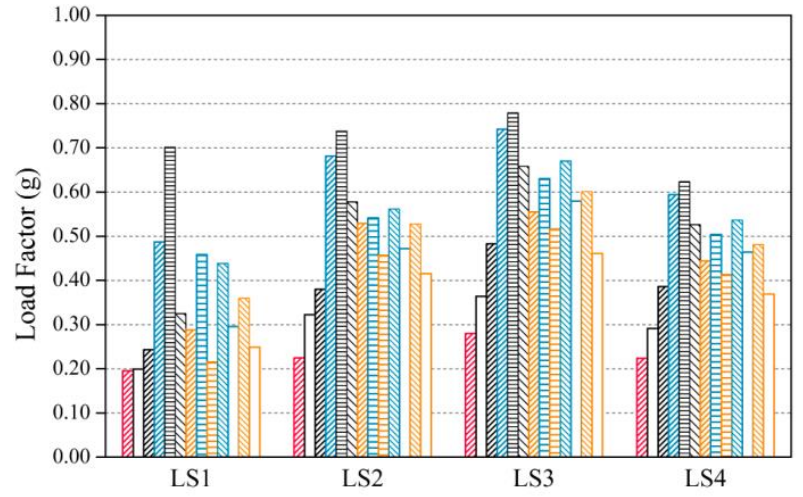

(a) RE1F_Y

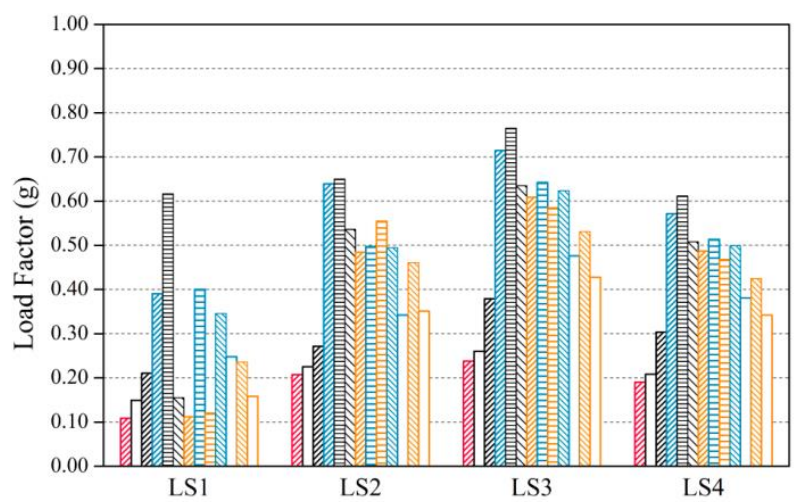

(c) RE2F_Y

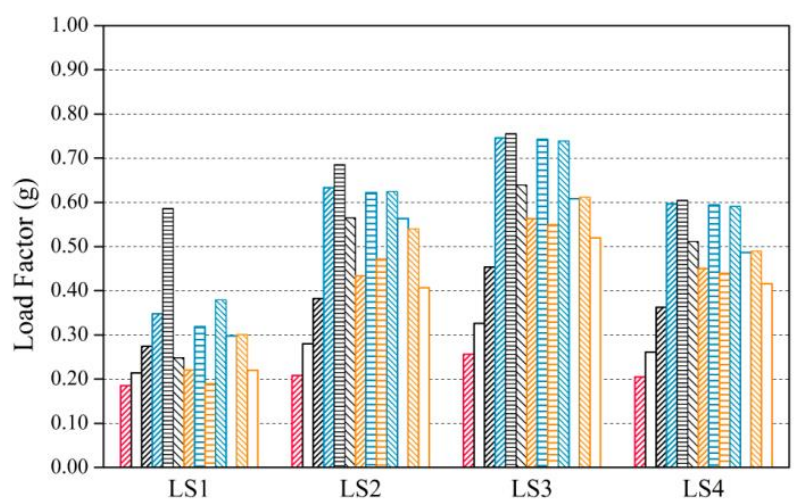

(e) STM3F_Y

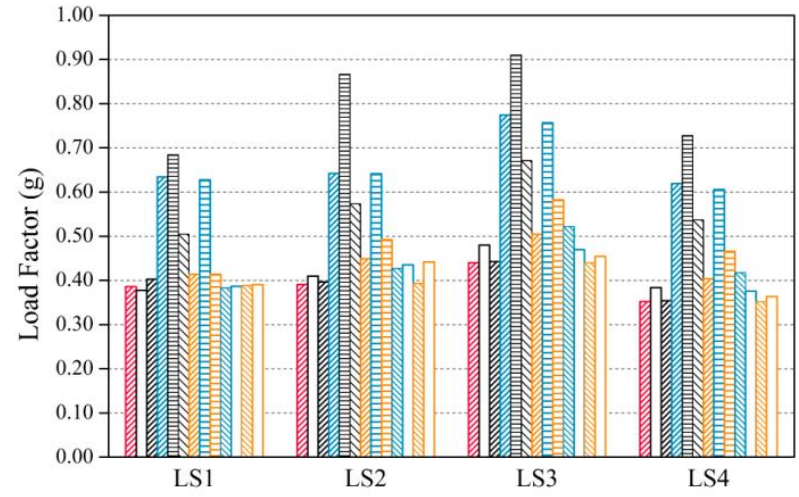

(b) RE1F_X

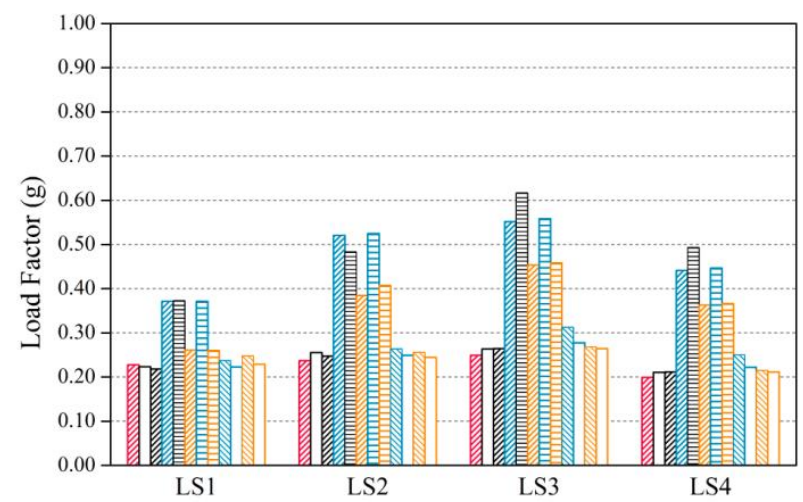

(d) RE2F_X

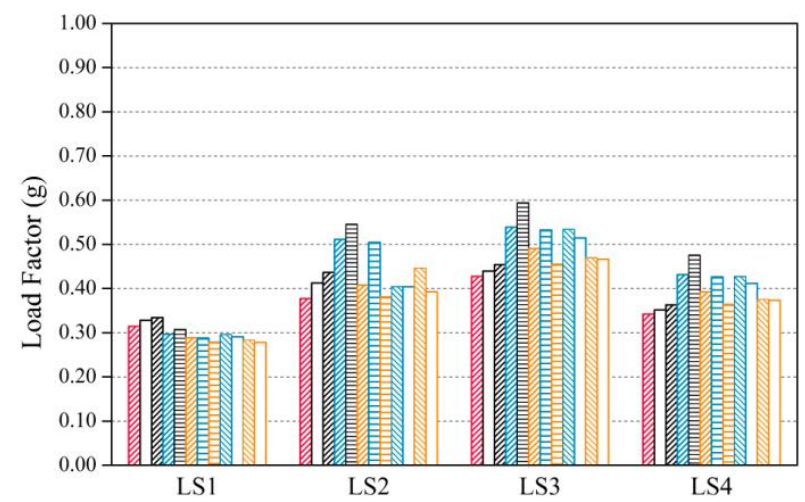

(f) STM3F_X

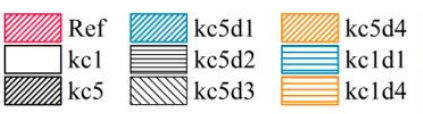

$\mathbb{1} \mathrm{kc} 5 \mathrm{~d} 1 \_\mathrm{kdc} 0$
$\mathrm{kcld} 1 \_\mathrm{kdc} 0$
$\mathrm{kc} 5 \mathrm{~d} 4-\mathrm{kdc} 0$

$\square \mathrm{kcld} 4 \_\mathrm{kdc} 0$

Figure 17. Comparison of load factors obtained for each limit state for all models in both orthogonal directions Additionally, Figure 18 presents the variation in terms of percentage of the Load Factor normalized by

141 the maximum capacity of the building according to different characteristics of the diaphragms. In all building typologies, the model with a rigid diaphragm well-connected to the walls (Model $k c 5 d 2$ ) showed the best 
Preprint version, Reference: Ortega, J., Vasconcelos, G., Rodrigues, H., Correia, M. Assessment of the influence of horizontal diaphragms on the seismic performance of vernacular buildings. Engineering Structures (2018). https://doi.org/10.1007/s10518-018-0318-8

performance, reaching the highest Load Factor values, and was used for the normalization. The graphs show the horizontal diaphragm.

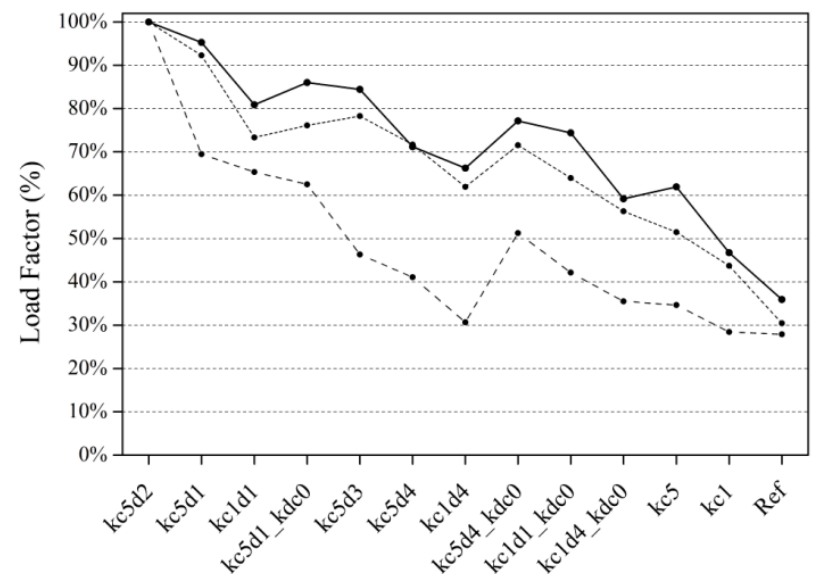

(a) RE1F_Y

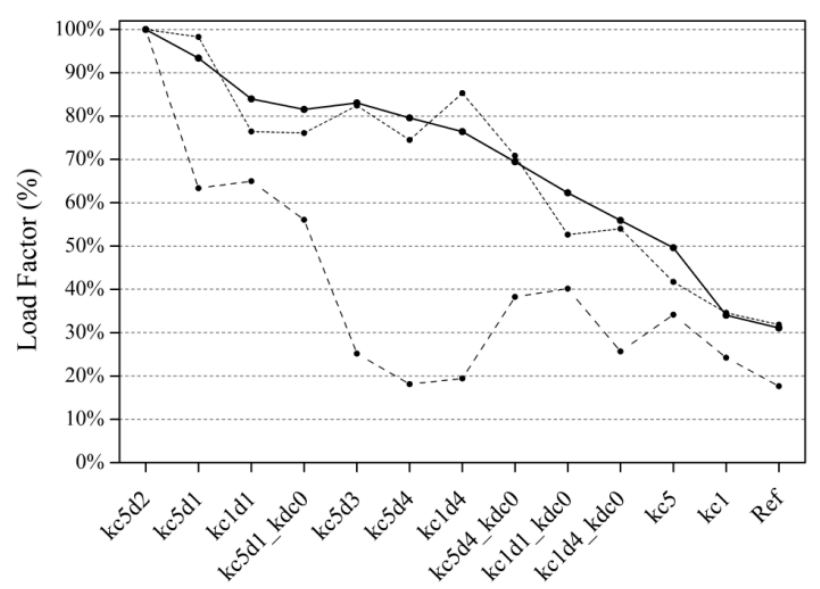

(c) RE2F_Y

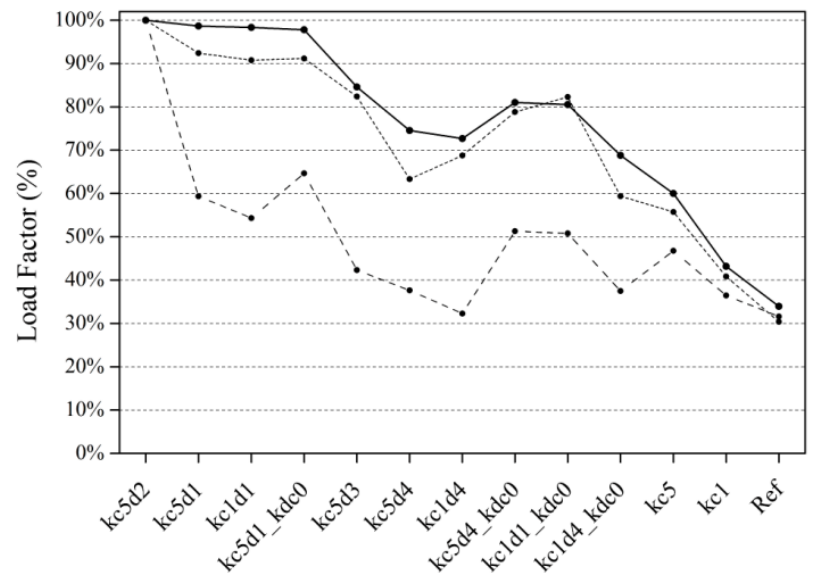

(e) STM3F_Y

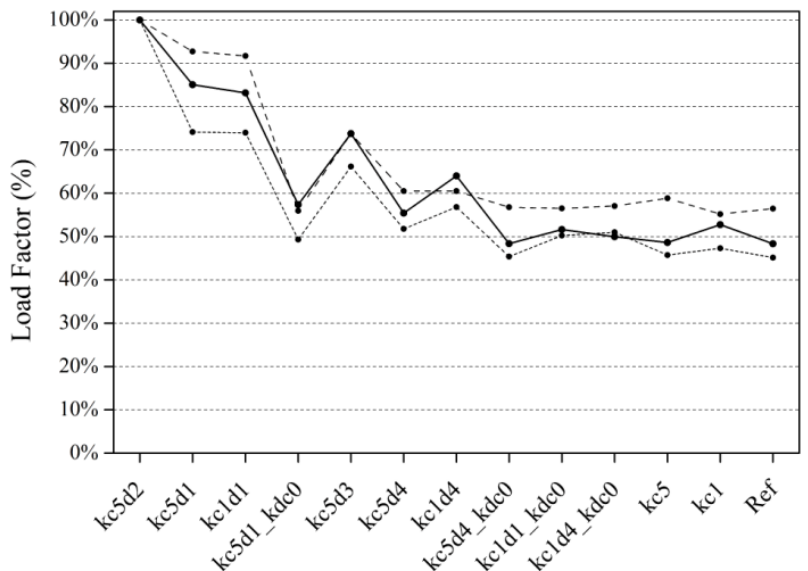

(b) RE1F_X

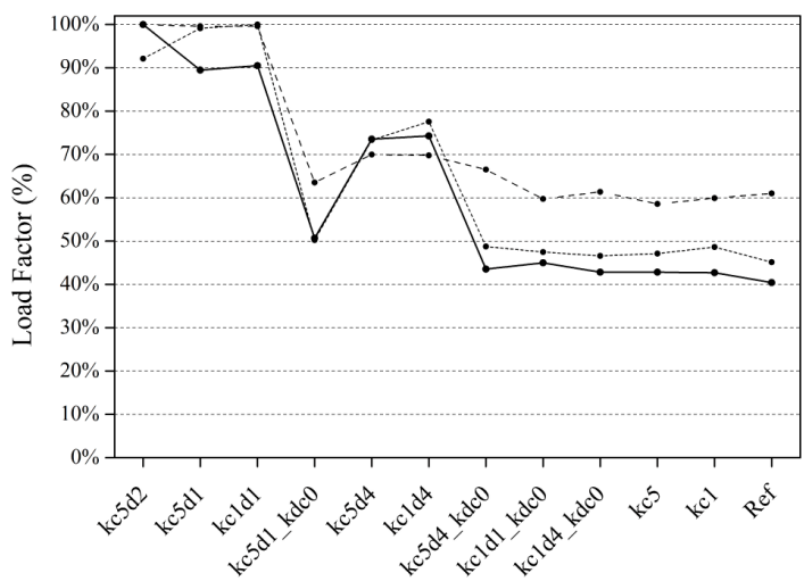

(d) RE2F_X

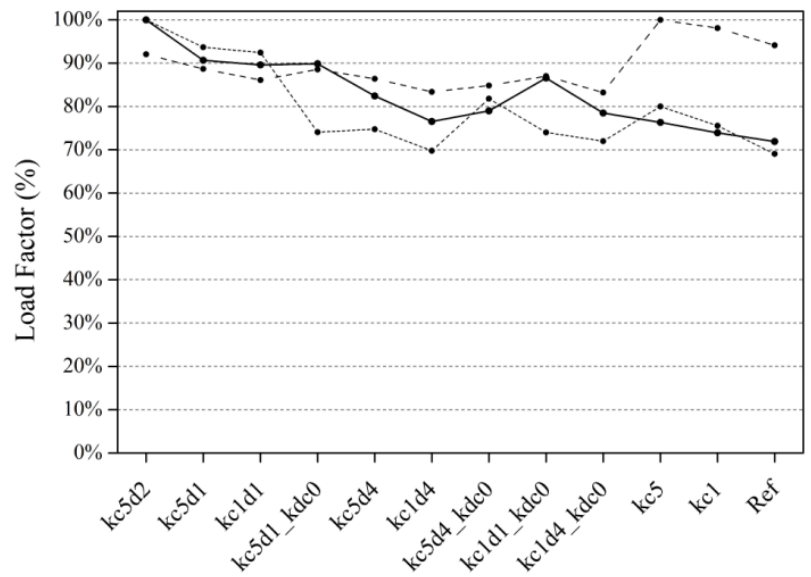

(f) STM3F_X

147 Figure 18. Variation of the load factor obtained for each limit state for all models in both orthogonal directions 
Preprint version, Reference: Ortega, J., Vasconcelos, G., Rodrigues, H., Correia, M. Assessment of the influence of horizontal diaphragms on the seismic performance of vernacular buildings. Engineering Structures (2018). https://doi.org/10.1007/s10518-018-0318-8

The variations of the load factor for the models loaded in the transversal Y direction show a clear almost linear decreasing trend, being similar for all limit states. However, it is noted that the influence of the diaphragm is lower in attaining the first limit state, which means that the onset of cracking is not avoided by the presence of the diaphragm unless this is significantly stiff. Figure 17 and 18 also confirm that the absence of the beneficial coupling effect of the beams in the longitudinal $\mathrm{X}$ direction results in almost the same seismic response in all cases with a flexible or poorly connected diaphragm. In fact, all models presenting a poor connection between the diaphragm sheathing and the walls lead to similar values of Load Factor.

\section{Definition of vulnerability classes}

Besides the gained insight on the influence of the different types of timber diaphragms in the seismic response of vernacular buildings, the results of the parametric analysis were used to propose a classification of timber diaphragm typologies according to their role in defining the seismic vulnerability of the building. In this scope, it should be noted that previous studies have already established seismic vulnerability classes for masonry buildings depending on the type of diaphragm they present. These classifications are usually part of seismic vulnerability assessment methods based on the vulnerability index method developed by Benedetti and Petrini (1984). These methods are based on post-earthquake damage observation and survey data, focusing on the identification and on the evaluation of constructive and material aspects that are more influential in the seismic response of the building. They constitute a reliable large-scale assessment and have been extensively applied in Italy (GNDT 1994) and Portugal (Vicente et al. 2011; Neves et al. 2012; Ferreira et al. 2013), obtaining useful and reliable results for the seismic vulnerability assessment of masonry buildings at an urban scale. In these empirical methods, each parameter considered to affect the seismic response of the building is associated to four classes of increasing vulnerability. Table 4 presents an example of classification based solely on a review of similar methodologies (Benedetti and Petrini 1984; GNDT 1994; Vicente 2008; Shakya 2014).

Table 4. Vulnerability classes proposed by other authors as part of seismic vulnerability assessment

171 methodologies according to the type of horizontal diaphragm.

\begin{tabular}{clc}
\hline Class & \multicolumn{1}{c}{ Description } \\
\hline A & Rigid or semi-rigid diaphragm well-connected to the walls. \\
\hline
\end{tabular}


Preprint version, Reference: Ortega, J., Vasconcelos, G., Rodrigues, H., Correia, M. Assessment of the influence of horizontal diaphragms on the seismic performance of vernacular buildings. Engineering Structures (2018). https://doi.org/10.1007/s10518-018-0318-8

Flexible diaphragm well-connected to the walls. Rigid or semi-rigid diaphragm well-connected to the walls but poorly preserved, showing signs of deterioration due to rotting of the timber elements or biological attacks.

Rigid or semi-rigid diaphragm poorly connected to the walls. Flexible diaphragm well-connected to the walls but poorly preserved, showing signs of deterioration due to rotting of the timber elements or biological attacks.

Taking the classification shown in Table 4 as a reference but using the results of the parametric analyses carried out, four seismic vulnerability classes were defined for vernacular buildings based on the type of horizontal diaphragm. As previously stated, load factors can be directly associated to equivalent static horizontal actions that the buildings can withstand before reaching the different structural limit states defined, regardless which is the failure mode observed on the building. That is why the variation of the load factors was selected as the basis for comparison and definition of the vulnerability classes. This classification is defined according to the variation of the load factor corresponding to the Life Safety Limit State (LS3), which is associated to the attainment of the maximum resistance of the building. As previously mentioned this limit state corresponds to significant structural damage but retains some lateral strength and margin against collapse, even if it cannot be used after the earthquake. The variation in percentage of the Load Factor corresponding to LS3 is plotted in masonry model in the longitudinal direction, as previously discussed.

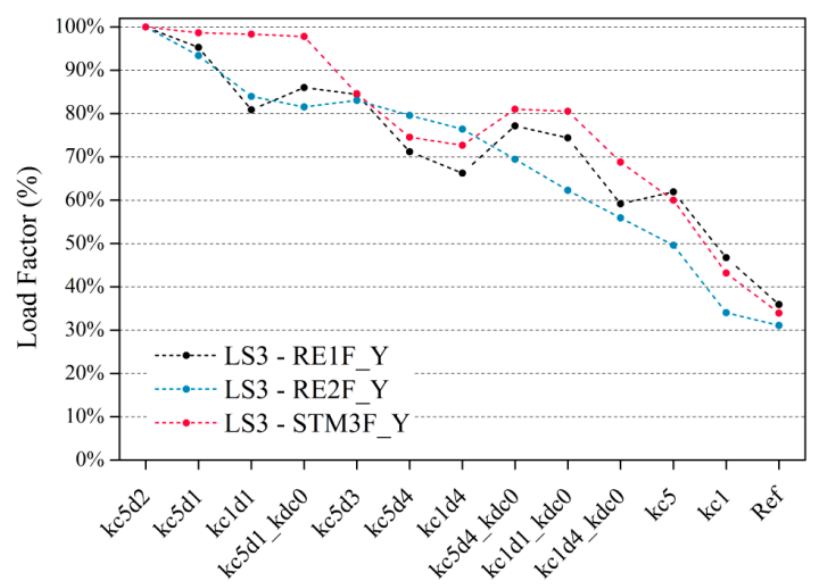

(a)

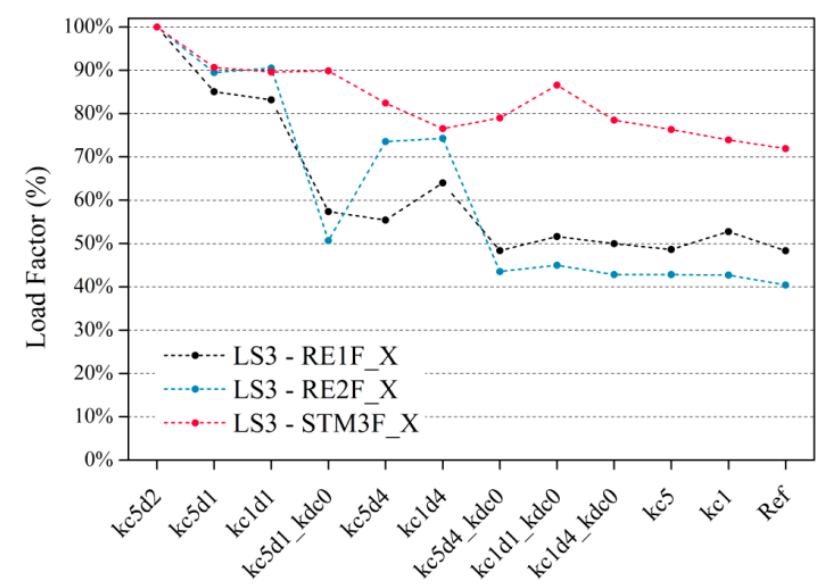

(b)

187 Figure 19. Variation of the load factor leading to the attainment of the maximum resistance (LS3) according to the type of horizontal diaphragm for the three different models evaluated: (a) Y direction; and (b) X direction. 
Preprint version, Reference: Ortega, J., Vasconcelos, G., Rodrigues, H., Correia, M. Assessment of the influence of horizontal diaphragms on the seismic performance of vernacular buildings. Engineering Structures (2018). https://doi.org/10.1007/s10518-018-0318-8

Herein, the definition of the seismic vulnerability classes for vernacular buildings according to the characteristics of the timber diaphragm is mostly based on the levels of variation of the load factor for the transversal (Y) direction, which is more sensitive to the type of diaphragm, see Figure 19a. In addition, the beneficial effect of all the constructive characteristics of the diaphragms previously defined, including the beams coupling effect between parallel walls, is optimized for the transversal direction. Figure 20 illustrates the criteria followed for the definition of the four classes. The maximum resistance of the reference building showing the worst performance is around $30 \%$ of the greatest maximum resistance of the building presenting a rigid diaphragm well-connected to the walls (Model $k c 5 d 2$ ). This variation range is divided equally into four parts and the definition of the four vulnerability classes is made according to this, leading to the classification shown in Table 5. It should be noted that the most unfavorable class is always considered: e.g. if one type of diaphragm leads to Class B for the one-floor rammed earth model but to Class $\mathrm{C}$ for the two-floor rammed earth model, it will be considered as Class C. Table 5 shows the vulnerability classes proposed for vernacular 201 buildings according to the type of horizontal diaphragm that they present. A qualitative description of the type 202 of horizontal diaphragm that belongs to each class is given as a reference.

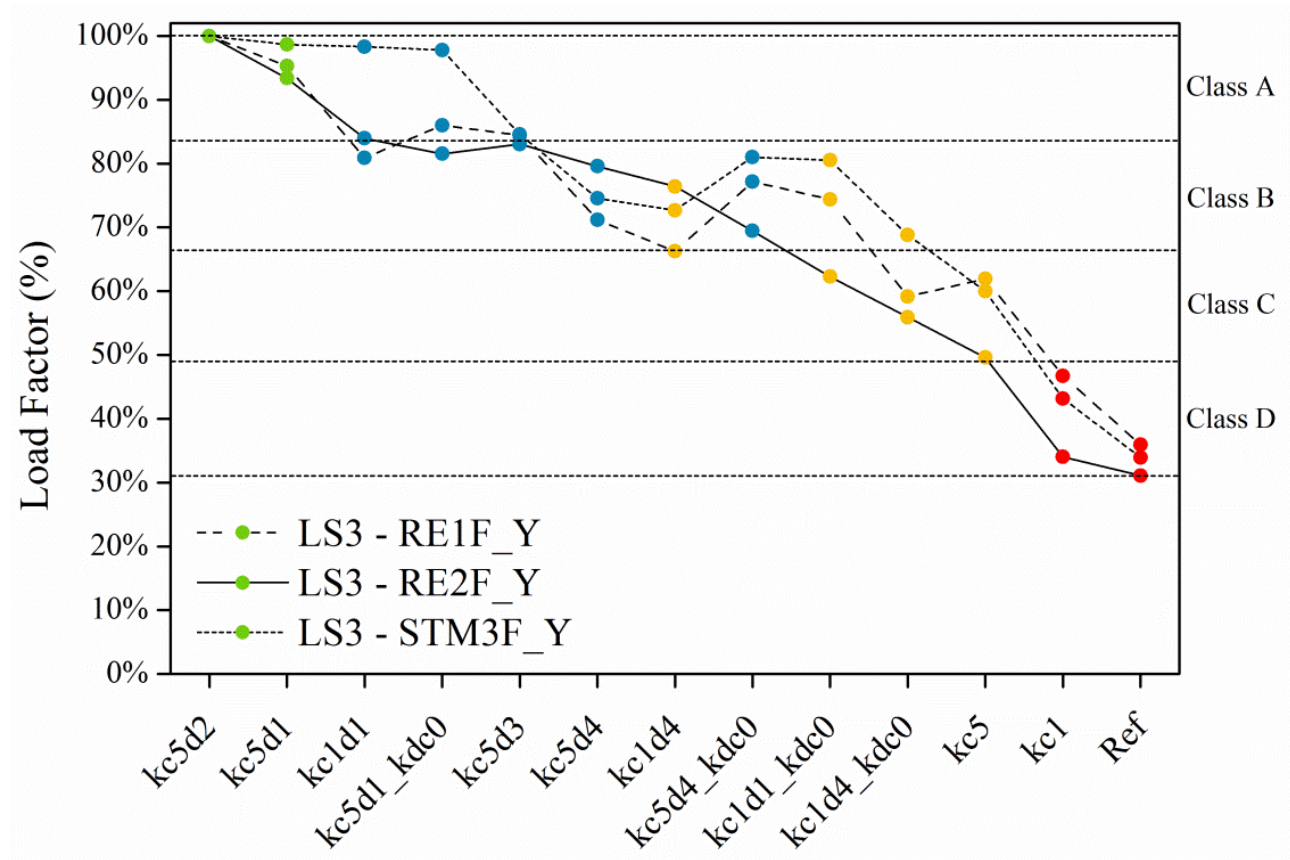

204 Figure 20. Variation of the load factor leading to the attainment of the maximum resistance (LS3) for the three 205 different models evaluated in the transversal (Y) direction. 
Preprint version, Reference: Ortega, J., Vasconcelos, G., Rodrigues, H., Correia, M. Assessment of the influence of horizontal diaphragms on the seismic performance of vernacular buildings. Engineering Structures (2018). https://doi.org/10.1007/s10518-018-0318-8

Nevertheless, given the results in the longitudinal direction, attention should be paid to the direction of the beams. If walls prone to out-of-plane collapse are not coupled with the beams and the floor is not well connected, the possible beneficial coupling effect of the beams cannot be taken into account and the building should always classify as Class D. It is considered that the classification suggested in Table 5 is in agreement with other classifications proposed in other methodologies that are based on post-earthquake damage

211 observation (Table 4). However, it provides more detailed information about the characteristics of the elements 212 composing horizontal timber diaphragms and their connection with other structural elements. Therefore, the 213 extensive numerical parametric study contributes to validate, bolster and extend the existing information on the 214 seismic vulnerability of buildings presenting traditional timber diaphragms by providing a more detailed 215 description and a more comprehensive analysis of the constructive aspects of horizontal diaphragms influencing 216 the seismic performance of vernacular buildings. Therefore, the classes proposed in Table 5 can be used 217 henceforth when performing a seismic vulnerability assessment for vernacular architecture based on the 218 definition of a vulnerability index. The numerical validation of the classes presented in this study is considered 219 to be helpful to strengthen the reliability of the vulnerability classes used in this type of seismic vulnerability 220 assessment methods, which typically only rely on empirical observation and expert opinion.

221 Table 5. Vulnerability classes proposed according to the type of horizontal diaphragm.

\begin{tabular}{|c|c|c|c|c|c|}
\hline Class & Description & Models & $\begin{array}{l}\text { Beam-to- } \\
\text { wall } \\
\text { connection } \\
\left(\mathrm{k}_{\mathrm{c}}\right)\end{array}$ & $\begin{array}{c}\text { Diaphragm-to- } \\
\text { wall } \\
\text { connection } \\
\left(\mathrm{k}_{\mathrm{fc}}\right)\end{array}$ & $\begin{array}{l}\text { Diaphragm } \\
\text { stiffness } \\
\left(\mathrm{k}_{\mathrm{f}}\right)\end{array}$ \\
\hline A & Rigid diaphragm well-connected to the walls. & $\begin{array}{l}k c 5 d 2 \\
k c 5 d 1\end{array}$ & Good & Good & Rigid \\
\hline \multirow{4}{*}{ B } & \multirow{4}{*}{$\begin{array}{l}\text { Rigid diaphragm well-connected to the walls but beams poorly } \\
\text { coupled with the walls. Rigid and flexible diaphragms poorly } \\
\text { connected to the walls but beams properly coupled with the walls. } \\
\text { Flexible diaphragm well-connected to the walls. Poor connections } \\
\text { can be either due to construction deficiencies or because of signs of } \\
\text { deterioration and decay of the timber elements, such as rotting and } \\
\text { biological attacks. }\end{array}$} & kcldl & Poor & Good & Rigid \\
\hline & & $k c 5 d 1 \_k d c 0$ & Good & Poor & Rigid \\
\hline & & $\begin{array}{l}k c 5 d 3 \\
k c 5 d 4\end{array}$ & Good & Good & Flexible \\
\hline & & $k c 5 d 4 \_k d c 0$ & Good & Poor & Flexible \\
\hline \multirow{4}{*}{ C } & $\begin{array}{l}\text { Flexible diaphragm well-connected to the walls but beams poorly } \\
\text { coupled with the walls. Rigid and flexible diaphragms poorly }\end{array}$ & kcld4 & Poor & Good & Flexible \\
\hline & connected to the walls with beams poorly coupled with the walls. & $k c 1 d 1 \_k d c 0$ & Poor & Poor & Rigid \\
\hline & walls achieving a coupling effect. Poor connections can be either due & $k c 1 d 4 \_k d c 0$ & Poor & Poor & Flexible \\
\hline & $\begin{array}{l}\text { to construction deficiencies or because of signs of deterioration and } \\
\text { decay of the timber elements, such as rotting and biological attacks. }\end{array}$ & $k c 5$ & Good & - & - \\
\hline
\end{tabular}


Preprint version, Reference: Ortega, J., Vasconcelos, G., Rodrigues, H., Correia, M. Assessment of the influence of horizontal diaphragms on the seismic performance of vernacular buildings. Engineering Structures (2018). https://doi.org/10.1007/s10518-018-0318-8

\section{Conclusions}

The influence of horizontal diaphragm typologies in the seismic response of masonry vernacular building has been investigated in the last decades. It has now been evaluated in this paper in an extensive way by conducting a parametric numerical analysis on representative earthen and stone masonry vernacular buildings. The results of the parametric analysis were also used to define seismic vulnerability classes for masonry and earthen structures presenting traditional timber horizontal diaphragms. This new proposed classification will be useful when performing a seismic vulnerability assessment of vernacular buildings based

230 on seismic vulnerability index methods. In this scope, it is considered that quantitative analysis was missing to 231 strengthen these methods that are typically based on existing empirical knowledge, particularly concerning vernacular constructions.

The seismic performance of traditional constructions is often compromised by the lack of adequate workmanship and poor quality materials, and by the typically poorly constructed timber floors working as horizontal diaphragms. In fact, the contribution of the diaphragm to enhance the seismic behavior of traditional

236 buildings depends both on its stiffness and on its proper connection with the resisting walls. However, the lack

237 of proper constructive detailing at the connections between the diaphragm structural elements and the load 238 bearing walls often prevents its possible beneficial effects. Different situations were modelled taking into account the aspects that were considered to be more influential in modifying the structural behavior of horizontal diaphragms: (a) beams-to-wall connection; (b) beams stiffness; (c) diaphragm stiffness; and (d) diaphragm-to-wall connection.

Three different reference models were constructed based on representative vernacular Portuguese constructions: (1) one-floor rammed earth building; (2) two-floor rammed earth building; and (3) three-floor stone masonry building. Variations on the type of horizontal diaphragm were performed in each of them according to the aspects mentioned. The results of the parametric analysis were mainly compared in terms of 
Preprint version, Reference: Ortega, J., Vasconcelos, G., Rodrigues, H., Correia, M. Assessment of the influence of horizontal diaphragms on the seismic performance of vernacular buildings. Engineering Structures (2018). https://doi.org/10.1007/s10518-018-0318-8

maximum load capacity and failure modes. With the exception of the beams stiffness, all the characteristics defined confirmed to have a crucial role in the seismic behavior of the building. Different types of horizontal diaphragm vary both the maximum capacity of the building and its collapse mechanism. Results showed that the maximum load capacity obtained for a building presenting a rigid diaphragm properly connected to the wall can be up to three times the maximum load capacity obtained for a building presenting a floor of negligible stiffness and poorly connected to the load bearing walls. Results also showed that similar patterns of variation of the maximum capacity of the buildings were obtained for all three different models.

The results obtained were used also to discuss and propose a classification of the seismic vulnerability of vernacular buildings according to the different types of horizontal diaphragm that they present. It is considered that the vulnerability classes proposed are in line with existing classifications available in the literature and strengthen their reliability, given that they were derived in an empirical basis. Finally, this classification is also aimed at understanding which types of horizontal diaphragm are more prone to increase the seismic vulnerability of a building, which can help also in making decisions on seismic strengthening strategies. Results can thus also be used for: (a) assessing the need of retrofitting of vernacular buildings; and (b) evaluating how to address this intervention by understanding which construction aspect of the diaphragm should be strengthened in order to improve the seismic behavior of the building.

\section{Acknowledgments}

The work presented in this paper was partly financed by FEDER funds through the Competitivity and

264 Internationalization Operational Programme - COMPETE and by national funds through FCT - Foundation for

265 Science and Technology within the scope of the project POC1-01-0145-FEDER-007633. This work was also 266 financed in the framework of the Portuguese Public Procurement Code, LOTE 3EC5 - Escola Secundária da 267 Anadia e Gafanha da Nazaré. 
Preprint version, Reference: Ortega, J., Vasconcelos, G., Rodrigues, H., Correia, M. Assessment of the influence of horizontal diaphragms on the seismic performance of vernacular buildings. Engineering Structures (2018). https://doi.org/10.1007/s10518-018-0318-8

271 Barbisan U, Laner F (1995) Wooden floors: part of historical antiseismic building systems. In: Bosch

272 E, Funiciello R, Guidoboni E, Rovelli A (eds) Earthquakes in the Past. Multidisciplinary Approaches, 273 Annali di Geofisica 38: 775-784

274 Benedetti D, Petrini V (1984) Sulla Vulnerabilità Di Edifici in Muratura: Proposta Di Un Metodo Di 275 Valutazione. L’industria delle Costruzioni 149(1): 66-74

276 Betti M, Vignoli A (2011) Numerical assessment of the static and seismic behaviour of the basilica of Santa 277 Maria all'Impruneta (Italy). Constructions and Building Materials 25(12): 4308-4324

278 Blondet M, Villa Garcia G, Brzev S, Rubiñós A (2011) Earthquake-Resistant Construction of Adobe 279 Buildings: A Tutorial. Earthquake Engineering Research Institute (EERI), Oakland, California, USA

280 Bothara J, Brzev S (2012) A Tutorial: Improving the Seismic Performance of Stone Masonry 281 Buildings. Earthquake Engineering Research Institute (EERI), Oakland, California, USA

282 Braga A, Estevão J (2010) Os Sismos e a Construção em Taipa no Algarve. In: Proc. of Sísmica 2010 $283-8^{\circ}$ Congresso de Sismologia e Engenharia Sísmica, Aveiro, Portugal

284 Brignola A, Podestá S, Pampanin S (2008) In-plane stiffness of wooden floor. In: Proc. of New 285 Zealand Society for Earthquake Engineering Conference, paper 49

286 Brignola A, Pampanin S, Podestà S (2012) Experimental evaluation of the in-plane stiffness of timber 287 diaphragms. Earthquake Spectra 28(4): 1687-1709

288 Bui Q-B, Morel J-C, Hans S, Meunier N (2008) Compression behaviour of non-industrial materials in 289 civil engineering by three scale experiments: the case of rammed earth. Materials and Structures 42(8): $290 \quad 1101-1116$

291 Correia M (2002) A Habitação Vernácula Rural no Alentejo, Portugal. In: Memorias del IV Seminario 292 Iberoamericano sobre vivienda rural y calidad de vida en los asentamientos rurales, Santiago del Chile, 293 Chile 
Preprint version, Reference: Ortega, J., Vasconcelos, G., Rodrigues, H., Correia, M. Assessment of the influence of horizontal diaphragms on the seismic performance of vernacular buildings. Engineering Structures (2018). https://doi.org/10.1007/s10518-018-0318-8

294 Correia M (2007) Taipa no Alentejo. Argumentum, Lisboa, Portugal

295 Correia M (2016) Experiences from the Past for Today's Challenges. In: The Road To Sustainable 296 Development. Chapter 6 - Traditional and generational change, La Fábrica, Fundación

297 Contemporánea, Madrid, Spain

298 D’Ayala DF, Paganoni S (2011) Assessment and analysis of damage in L'Aquila historic city centre 299 after 6th April 2009. Bull Earthquake Eng 9(1): 81-104

300 Fernandes J, Mateus R (2012) Energy efficiency principles in Portuguese vernacular architecture. In: 301 International Conference BSA 2012, Porto, Portugal

302 Ferreira F, Vicente R, Varum H, Costa A, Costa AA (2012) Out-of-plane seismic response of stone 303 masonry walls: Experimental and analytical study of real piers. In: Proc. of the 15th World Conference 304 on Earthquake Engineering, Lisbon, Portugal

305 Ferreira F, Vicente R, Mendes da Silva JAR, Varum H, Costa A (2013) Seismic vulnerability 306 assessment of historical urban centres: case study of the old city centre in Seixal, Portugal. Bulletin of 307 Earthquake Engineering 11(5): 1753-1773

308 Gallego R, Arto I (2014) Evaluation of seismic behaviour of rammed earth structures. In: Mileto, 309 Vegas, García-Soriano \& Cristini (eds) Earthen Architecture: Past, Present and Future, Taylor \& 310 Francis Group, London, UK

311 Gattesco N, Macorini L, Benussi F (2007) Retrofit of wooden floors for the seismic adjustment of 312 historical buildings with high reversible techniques. Seismic Engineering in Italy. In: Proc. of the XII 313 National Conference, 10-14 June, Pisa, Italy

314 GNDT (1994) Scheda di esposizione e vulnerabilità e di rilevamento danni di primo livello e secondo 315 livello (muratura e cemento armato). GNDT (Italian Group for the defense against earthquakes), 316 Rome, Italy 
Preprint version, Reference: Ortega, J., Vasconcelos, G., Rodrigues, H., Correia, M. Assessment of the influence of horizontal diaphragms on the seismic performance of vernacular buildings. Engineering Structures (2018). https://doi.org/10.1007/s10518-018-0318-8

317 Giongo I, Dizhur D, Tomasi R, Ingham J (2014) Field testing of flexible timber diaphragms in an 318 existing vintage URM building. Journal of Structural Engineering 141, Special issue: Field testing of 319 bridges and building

320 Gomes MI, Lopes M, de Brito J (2011) Seismic resistance of earth construction in Portugal. 321 Engineering Structures 33(3): 932-941

322 ICOMOS (1999) Charter on the Built Vernacular Heritage. International Council on Monuments and 323 Sites (ICOMOS), ICOMOS $12^{\text {th }}$ General Assembly, Mexico

324 Ingham J, Biggs D, Moon L (2011) How did unreinforced masonry buildings perform in the February 3252011 Christchurch earthquake? Struct Eng 2012 89(6): 14-18

326 Jaquin P (2008) Analysis of Historic Rammed Earth Construction. PhD Dissertation, Durhan 327 University

328 Lourenço PB, Krakowiak F, Fernandes FM, Ramos LF (2007) Failure analysis of Monastery of 329 Jerónimos, Lisbon: how to learn from sophisticated numerical models. Engineering Failure Analysis $330 \quad 14: 280-300$

331 Lourenço PB (2009) Recent advances in masonry structures: micromodelling and homogenization. In: 332 Galvanetto U, Ferri Aliabadi MH (eds) Multiscale modeling in solid mechanics: computational 333 approaches. Imperial College Press: 280-300

334 Lourenço PB, Mendes N, Ramos LF, Oliveira DV (2011) On the analysis of masonry Structures 335 without box behavior. International Journal of Architectural Heritage: Conservation, Analysis and 336 Restoration 5(4-5): 369-382

337 Lourenço PB, Trujillo A, Mendes N, Ramos LF (2012) Seismic performance of the St. George of the 338 Latins church: Lessons learned from studying masonry ruins. Engineering Structures 40: 501-518 
Preprint version, Reference: Ortega, J., Vasconcelos, G., Rodrigues, H., Correia, M. Assessment of the influence of horizontal diaphragms on the seismic performance of vernacular buildings. Engineering Structures (2018). https://doi.org/10.1007/s10518-018-0318-8

339 Lourenço PB, Karanikoloudis G, Mendes N, Corallo C (2015) Assessment of the South aisle in 340 Canterbury. In: Proc. of the 2nd International Conference on Preservation, Maintenance and 341 Rehabilition of Historical Buildings and Structures, Porto, Portugal

342 Lourenço PB, Karanikoloudis G, Greco F (2016) In situ testing and modeling of cultural heritage 343 buildings in Peru. In: Proc. of the 10th International Conference on Structural Analysis of Historical 344 Constructions, SAHC 2016, Leuven, Belgium

345 Lozano G, Lozano A (1995) Curso de técnicas de intervención en el patrimonio arquitectónico. Tomo 346 1. Reestructuración en madera. Ed. Cons. Técn. de Contrucción CB, Gijón, Spain

347 Magenes G, Penna A, Rota M, Galasco A, Senaldi I (2014) Shaking table test of a full-scale stone 348 masonry building with flexible diaphragms. International Journal of Architectural Heritage 8(3): 349$349 \quad 375$

350 Mallardo V, Malvezzi R, Milani E, Milani G (2008) Seismic vulnerability of historical masonry 351 buildings: a case study in Ferrara. Eng Struct 30: 2223-41

352 Mendes N, Lourenço PB (2009) Seismic assessment of masonry "Gaioleiro" buildings in Lisbon, 353 Portugal. Journal of Earthquake Engineering 14(1): 80-101

354 Mendes N, Lourenço PB (2015) Seismic Vulnerability of Existing Masonry Buildings: Nonlinear 355 Parametric Analysis. In: Psycharis I., Pantazopoulou S., Papadrakakis M (eds) Seismic Assessment, 356 Behavior and Retrofit of Heritage Buildings and Monuments. Computational Methods in Applied 357 Sciences, vol 37. Springer, Cham

358 Miccoli L, Oliveira DV, Silva R, Müller U, Schueremans L (2014) Static behaviour of rammed earth: 359 experimental testing and finite element modelling. Materials and Structures 48: 3443 
Preprint version, Reference: Ortega, J., Vasconcelos, G., Rodrigues, H., Correia, M. Assessment of the influence of horizontal diaphragms on the seismic performance of vernacular buildings. Engineering Structures (2018). https://doi.org/10.1007/s10518-018-0318-8

360 Mouyiannou A, Rota M, Penna A, Magenes G (2014) Identification of Suitable Limit States from 361 Nonlinear Dynamic Analyses of Masonry Structures. Journal of Earthquake Engineering 18(2): 231$362 \quad 263$

363 Nakamura Y, Derakhshan H, Magenes G, Griffith MC (2017) Influence of diaphragm flexibility on 364 seismic response of unreinforced masonry buildings. Journal of Earthquake Engineering 21(6): 935365960

366 Neves F, Costa A, Vicente R, Oliveira CS, Varum H (2012) Seismic vulnerability assessment and 367 characterization of the buildings on Faial Island, Azores. Bull Earthquake Eng 10(1): 27-44

368 NTC (2008) Norme Tecniche per le Costruzioni. D.M. 14 gennaio 2008, S.O. No. 30, G.U. No. 369 29/2008. Rome, Italy

Ortega J, Vasconcelos G, Rodrigues H, Correia M, Lourenço PB (2017) Traditional earthquake 371 resistant techniques for vernacular architecture and local seismic cultures: A literature review. Journal 372 of Cultural Heritage

373 Rota M, Penna A, Magenes G (2010) A methodology for deriving analytical fragility curves for masonry buildings based on stochastic nonlinear analyses. Engineering Structures 32(5): 1312-1323

375 Rudofsky B (1964) Architecture without architects - A Short Introduction to Non-Pedigreed 376 Architecture. Museum of Modern Art, New York, USA Saloustros S, Pelà L, Roca P, Portal J (2014) Numerical analysis of structural damage in the church of 378 the Poblet Monastery. Engineering Failure Analysis 48: 41-61

379 Shakya M (2014) Seismic Vulnerability Assessment of Slender Masonry Structures. PhD Dissertation, 380 Universidade de Aveiro

381 Sorrentino L, Liberatore L, Liberatore D, Masiani R (2013) The behaviour of vernacular buildings in the 2012 Emilia earthquakes. Bulletin of Earthquake Engineering 12(5): 2367-2382 
Preprint version, Reference: Ortega, J., Vasconcelos, G., Rodrigues, H., Correia, M. Assessment of the influence of horizontal diaphragms on the seismic performance of vernacular buildings. Engineering Structures (2018). https://doi.org/10.1007/s10518-018-0318-8

383 TNO (2011) DIsplacement method ANAlyser. User's manual, release 9.4.4. Netherlands

384 Tomazevic M, Lutman M, Velechovsky (1991) The influence of rigidity of floor on the seismic 385 behaviour of old stone-masonry buildings. European Earthquake Engineering 3: 28-41

386 Vicente R (2008) Estratégias e metodologias para intervenções de reabilitação urbana. Avaliação da 387 vulnerabilidade e do risco sísmico do edificado da Baixa de Coimbra. PhD Dissertation, Universidade 388 de Aveiro

389 Vicente R, Parodi S, Lagomarsino S, Varum H, Mendes da Silva JAR (2011) Seismic vulnerability 390 and risk assessment: case study of the historic city centre of Coimbra, Portugal. Bulletin of Earthquake 391 Engineering 9(4): 1067-1096

392 Vintzileou E, Mouzakis C, Adami CE, Karapitta L (2015) Seismic behaviour of three-leaf stone 393 masonry buildings before and after interventions: Shaking table tests on a two-storey masonry model. 394 Bulletin of Earthquake Engineering 13(10): 3107-3133

395 Whitney R, Agrawal A (2015) Seismic performance of flexible timber diaphragms: damping, force396 displacement and natural period. Engineering Structures 101: 583-590

397 Wilson A, Quenneville P, Ingham J (2013) Natural period and seismic idealization of flexible timber 398 diaphragms. Earthquake Spectra 29(3): 1003-1019

399 Wilson A, Quenneville PJH, Ingham JM (2014) In-plane orthotropic behavior of timber floor 400 diaphragms in unreinforced masonry buildings. Journal of Structural Engineering 140(1) 